\title{
Understanding the regional innovation capacity in China after economic reforms
}

\begin{abstract}
Our study aims to examine the drivers of China's regional innovation capacity. Drawing from innovation system literatures, our study proposes that regional innovation capacity can be determined by (a) innovation actors (higher education institutions, enterprises, and public research institutes); (b) innovation inputs (financial capital and human resource) and (c) international interactions. The main finding was the significant impact of higher education institutions demonstrating higher education institutions are crucial innovation actors. The interact effect also found between Foreign Direct Investment and Science and Technology investment suggests governments should pay more attention to the indirect impact of drivers in building regional innovation capacity in China.
\end{abstract}

Keywords: Regional innovation, innovation system, China, Foreign Direct Investment, Asia 


\section{Understanding the regional innovation capacity in China after economic reforms}

\section{Introduction}

China has been transitioning and transforming from a centrally planned regime to a marketoriented system since the economic reform started in 1978. Its environment for innovation has produced a dynamic tension between old and new, between foreign and indigenous, and between cultural values and practicality (Baark, 2007). Innovation is a crucial factor for economic development and China is an influential country in the world economy. These two factors make it even more important to study the phenomenon of innovation in China. However, most NIS studies focusing on rapid economic development are based on the Asian Tigers or countries in South East Asia, and there is a need to study IS in the context of other development models (Asheim \& Vang, 2006). Researchers have studied various aspects of China's NIS and RIS, for example, the transition process of science and technology system reform (Zhong \& Yang, 2007), innovation index (Ji \& Zhao, 2008), and the measurement of RIS performance (Wu, Zhou, \& Liang, 2010).

Although there are many studies on China's NIS, they mainly focus on one part of China, for example Southern China (Barbieri, Di Tommaso, \& Huang, 2010), or Beijing and Shenzhen (Chen \& Kenney, 2007; Guan, Yam, \& Mok, 2005; Zhu \& Tann, 2005). Only a few researchers have studied the differences in NIS with consideration of the innovation level of regions (Ji \& Zhao, 2008). However, this study investigates the differences between drivers using a qualitative approach, which only shows the differences in the factors among regions, but does not show how influential individual factors are in driving innovation capacity in the regions. Therefore, the differences in innovation drivers among regions of different innovation levels are not yet well understood. Thus, our study aims to provide new 
insight into China's NIS development by investigating innovation capacity at the regional level, namely Regional Innovation Capacity (RIC) across China. More specifically, we propose that RIC can be determined by (a) institutional environment; (b) innovation actors and (c) interactions among actors.

\section{Determinants of Regional Innovation Capacity (RIC) through Regional Innovation System (RIS) framework}

The NIS approach assumes homogeneity within countries, but this is not necessarily the case for China. Although many studies may adopt NIS to explain the innovation capacity at the regional level, but the concept of RIS is more appropriate in explaining regional differences in innovation capacity and economic strength (D’Allura, Galvagno, \& Mocciaro Li Destri, 2012). RIS usually consists of a set of interacting private, semi-private and public organisations, interacting within institutions (Asheim, Coenen, \& Svensson-Henning, 2003). This framework supports the generation, exploitation and dissemination of knowledge and thus supports innovative activities on a regional level (D’Allura et al., 2012).

The concept of RIS has been popularly used by academic researchers and policy makers since early 1990s. However, there are no commonly accepted definitions of RIS. Cooke and his colleagues $(1997 ; 1998)$ point out RIS consist of firms and other organisations systematically engaged in interactive learning, embedded in a specific institutional environment. The linkages among the organisations can be specified in terms of flow of knowledge and information, flow of investment funding, flow of authority and some informal arrangements such as networks (Cooke et al., 1997). Asheim and Isaksen (1997) state an RIS sits on a production structure and institutional infrastructure. Later Howells (1999) argued RIS encompass a localised network of actors and institutions in the public and private sectors whose activities and interactions generate, import, modify, and diffuse new technologies 
within and outside the region. In Doloreux's (2003) view, RIS is a set of interactions between private and public interests, formal institutions, and other organisations that function according to organisational and institutional arrangements and relationships conducive to the generation, use, and dissemination of knowledge.

According to the various definitions of RIS mentioned above, RIS is (1) a social system; (2) involves interactions among different sets of actors; (3) through interactions, able to enhance the innovation performance of a region. Therefore the most important elements of RIS are the institutional environment, innovation actors, and interactive activities that connect the former two elements. The system of regional innovation works as all the elements "condition and constrain one another" with "reasonable defined function" (Fleck, 1993, p. 17). In other words, innovation actors generate, use, and diffuse innovation through interactive activities under the specific institutional arrangements within a region (Chung, 2002; Doloreux, 2002; Doloreux \& Parto, 2009; Howells, 1999). Hence, institutional environments are the context of innovation, which all innovation activities are embedded in; innovation actors are where the innovations are from and the objects for which institutional arrangements are made; and interactions are the key activities which link innovation actors and institutional environments together.

Based on the review above, in this study, RIS is defined as a set of innovation actors and inputs engaged in the innovation process through interactions embedded in specific institutional environments within a region.

\subsection{Innovation actors}

In RIS, innovation actors mainly refer to the organisations who generate innovations directly, namely firms, research institutes, universities, and government agencies (Cooke et al., 1997; Doloreux, 2002). In the system, each actor has its fundamental role. Firms generalise 
productive activities (Etzkowitz, 2008); research institutes most frequently influence the generation and development of new ideas for innovative firms (Fritsch \& Schwirten, 1999), and serve as technology incubators (K. Chen \& Kenney, 2007) ; universities preserve and transfer knowledge (Iammarino, 2005; Mathews \& Hu, 2007), and provide human capital (K. Chen \& Kenney, 2007); and some government agencies generate and diffuse innovations, others guarantee innovation policies (Etzkowitz, 2008). Besides the basic tasks, each of them "takes the role of the other" according to the Triple-helix theory (Etzkowitz, 2008).

Another important role of innovation actors is to be a rule-follower. They are the objects of all innovation policies. Innovation policies establish the context for innovation development (William \& Balaji, 1979) to improve the innovation capacity. As innovation actors are innovation generators and diffusers they are the subjects innovation policies want to affect in order to achieve the government's innovation development objectives. On the flip side, following the government's innovation policies helps innovation actors get more resources and support for innovation activities (Oliver, 1997). Obeying the laws also helps protect and promote their innovations and pursuing the directions government prioritises helps them seize more opportunities for long-term development. Therefore, the influences between innovation policies and innovation actors are two-way.

\subsection{Innovation inputs}

The NIS and RIS approaches conceptualize technological development in terms of inputs (e.g. science funding). Additionally, these approaches view innovation efforts as intimately linked to broader macroeconomic and educational policies. More specifically, the development of human capital via education and training is essential for fostering absorptive capacity. Accordingly, the Chinese government realised the importance of Science and Technology (S\&T) in economic development. Several programs were launched after the 
reform, in order to build the nation with science and education (J. Li \& Li, 2008). The research institutions and universities were given more autonomy and were encouraged to establish links with enterprises through various mechanisms, such as technical service, co$\mathrm{R} \& \mathrm{D}$, and technology investment. The governments put great effort into building up technology markets to facilitate technology transformation. They also dedicated resources to reshaping the relationship between knowledge producers and users. An excellence-based allocation mechanism was also introduced to re-allocate public R\&D funds.

\subsection{Interaction}

Innovative capacity in regions depends not only on the innovative capacities of organisations, but on their interactions with each other and the public institutions in a region (Doloreux, 2002), as interactions make the capabilities of actors shift and grow (Carlsson, Jacobsson, Holmen, \& Rickne, 2002). The greater the interactions among components of a system, the more dynamic and flexible the system is and the more sustainable the changes in the environment will be (Carlsson et al., 2002). Moreover, the effect of innovation policies is determined to a great extent by the degree of the interaction between industry and regulatory authorities (Rothwell, 1992), which means interaction may influence the change of institutional environment in which innovation actors are embedded as well.

With respect to domestic interactions, Li (2009) used the proportion of S\&T funds raised from firms by universities and research institutes to measure the interactions among firms, universities and research institutes and contract value in the regional technology market to measure interactive learning. These two measures together consider both financial capital flow and knowledge flow. In view of knowledge as a commodity, the value of domestic technology contracts in technology market is employed to measure the technological interactions between innovation actors. A strong technology market is 
important for technology transfer and utilisation of patents across regions, while the measure of technology contracts set by the State Science and Technology Commission captures activities of transforming patented technologies into commodities (Johnson \& Liu, 2011). Hence, technology contracts represent both knowledge flow and interactive learning between regions and within a region.

Beside domestic interactions, the development of RIS is becoming more dependent on external linkages. Technological knowledge from advanced countries is an important connection for China (Asheim \& Vang, 2006; Giuliani, Rabellotti, \& Dijk, 2005). Hence, international interactions are covered in the analysis as well. Regions can access foreign technology and knowledge through Foreign Direct Investment (FDI), international trade and the mobility of human capital across borders and collaborations (Liang, 2008; Z. Liu, 2008; Peng \& Wang, 2000; Zhang \& Rogers, 2009). Domestic innovation actors can benefit both from foreign technology providers and users.

Other than FDI, international trade is another channel to reach advanced technologies and knowledge to improve innovation capacity of a country or a region. Technology traded with international innovation actors will increase the quality of goods (Spulber, 2008), as foreign users may facilitate exporters to improve their product to meet the criteria of foreign markets (Chuang \& Hsu, 2004; Lin \& Lin, 2010). Accordingly, both FDI and international trade may have direct and indirect impact on the development of innovation capacity in China.

\section{Patents as an indicator for reginal innovation capacity}

To measure the innovation capacity of regions, our study, following Li (2009), employs the number of domestic patents as the proxy for commercially valuable innovation output. Patent data are the favoured, and most commonly used, indicators in measuring innovation output in 
regional innovation studies. Although patent information is not perfect, it provides a fairly reliable measure of innovation activity (Acs, Anselin, \& Varga, 2002; Acs \& Audretsch, 1989). Practically, patent statistics are easy to access, available from various patent databases. It is possible to use patent data for longitudinal analysis (Acs \& Audretsch, 1989) and the dynamics of technological change (Acs et al., 2002). It seems patent statistics offer the best available output indicator for innovation activities (Freeman, 2004).

Meanwhile, issues associated with equating patent counts with the level of innovation activity are widely documented in the literature (Acs et al., 2002; Archambault, 2002; Griliches, 1990; Hagedoorn \& Cloodt, 2003; Trajtenbery, 1990). According to Griliches' (1990) argument not all innovations are patentable, and not all innovations are patented, which questions the representativeness of patents on innovations. Accordingly, some alternative indicators for innovation were used in some empirical studies, such as the number of new products (Fritsch, 2002), new product sales (Xielin Liu \& White, 1997), and literature-based innovation counts (Acs et al., 2002). However, these indicators have similar pitfalls as patents, for instance the measurement of economic value of innovations and the quality of innovations.

In contrast to some initial studies on innovation capacity (Furman, Porter, \& Scott, 2002; Hu \& Mathews, 2005), domestic patents rather than international patents were used. Although international patents are a good proxy for commercially relevant innovations, they do not reflect the entire spectrum of innovative activities in a country, especially a developing one (Krammer, 2009). Besides, domestic patents reduce the source bias by using international patents from two different databases such as in Furman's (2002) work, as the criteria for a patent to be granted in each database may differ. Moreover, domestic patents are more comparable because all the regions are subject to the same national patenting laws, 
go through the same patenting procedures, and pay the same cost. Therefore domestic patents are much more suitable for our study than international patents.

\section{The focus}

Innovation capacity has been acknowledged as a critical force in national economic development, not only for developed countries (Nelson, 1993; Porter, 1990), but also for latecomers such as China and India (Fan, 2011). The review above shows the importance of interaction in the development of RIS; it joins innovation actors and institutional environment (e.g. innovation policies) together. Therefore, the institutional environment, innovation actors and their interactions can significantly influence on national innovation level (which can be indicated by granted patents). To better understand this assumption, our study analyzed secondary data from various official statistic yearbooks yields in order to unpack the relationship among the institutional environment (as innovation inputs), innovation actors, their interactions and innovation activity (through granted patents).

\section{Method}

\subsection{Samples}

There are 33 administrative regions in PRC, including 22 provinces. Regions in China are unevenly developed and RIC is also uneven. For example, the S\&T intensity of Beijing is much higher than that of other regions, and Shaanxi is in the top tier of S\&T intensity. Since the administrative classification mainly considers geographical differences and economic development, it is not directly applicable to this study.

\subsection{Procedures}

We used secondary data (e.g. official statistics ranging from 1991-2011) because it can provide longitudinal information to uncover the change in impact of explanatory variables on 
RIC. Aside from the statistics, qualitative data were also collected. Qualitative data were used to supplement the quantitative analysis, and to assist in uncovering the big picture and understanding the results. The main qualitative data for our study were government documents, including implemented developmental plans, policies, laws, and regulations, published development and research reports written during the study period, and related information from newspapers, journals, and industry associations.

\subsection{Measures}

To enable comparison of regions of vastly different sizes, all financial variables were divided by regional GDP and other variables were divided by regional population. To ensure distributions are approximately normal, the logarithm transformation of most metric variables was used.

\subsubsection{Innovation actors}

The main innovation actors considered in innovation systems are firms, universities and research institutes. Universities in IS are considered in a broad way. In China universities can be referred to as higher education institutions, which consist of universities, special colleges, such as medical schools and musical colleges, and professional technology colleges. Accordingly, the number of HEI in each region is included.

There are many types of firms in China in terms of the classification criteria. The total number of all types of firms is not accessible for the study period. Thus, the number of large and medium-sized industrial enterprises was used to explore the influence of firms on innovation capacity. According to the latest criteria issued for firm classification in 2003 , for a large-sized industrial enterprise the annual operational revenue should be over 300 million Chinese Yuan, and the number of employees should over 2000; for a medium-sized industrial 
enterprise the operational revenue should be between 30 million and 300 million Chinese Yuan, and the number of employees between 300 and 2000 (NDRC).

Research institutes are not included in the analysis. However, this does not mean they are not important, as a matter of fact, they are a critical factor in China's NIC (Hu \& Mathews, 2008). With the reform of research institutes, however, the number of research institutes is not a suitable proxy for investigating its effect on RIC. Many RI are merged with or transformed into enterprises (Huang, 2007) and the statistical approaches differ in different years according to the public official data, which means the data are not comparable. Therefore, only the number of HEI (ACTOR1) and the number of large and medium-sized industrial enterprises (ACTOR2) are included as innovation actors in the analysis.

\subsubsection{Innovation inputs}

As described earlier, the institution environment is defined as a set of rules, regulations or policies which influence innovation activities. Another word, this environment can be acted as key capital input for innovation production. A range of innovation inputs has been employed in previous studies. Resource commitments such as funding for science and technology activities, R\&D expenditure (Evangelista, Iammarino, Mastrostefano, \& Silvani, 2001; Freeman, 2004; Pan, 2007; Park \& Park, 2003), scientists and engineers (Lundvall, 2007), and knowledge stock such as patent stock (Zabala-Iturriagagoitia, Voigt, GutiérrezGracia, \& Jiménez-Sáez, 2007) are considered as the most direct input factors to innovation activities.

With regard to financial input, funding for S \& T activities was included. The original data $^{1}$ were divided by regional GDP to control the effect of the size differences among

\footnotetext{
${ }^{1}$ Patent Statistic Yearbook from 1991 to 2009; China Statistic Yearbook from 1992 to 2011; and China Statistic Yearbook on Science and
} Technology, from 1992 to 2009. 
regions, and then they were transformed into the format of a logarithm to ensure normal distribution. Since funding for science and technology can be used for all science and technology related activities, including $R \& D$ activities, purchase or construction of fixed assets may represent the effort put into innovation development better than $R \& D$ expenditure.

In terms of human resources, the number of scientists and engineers employed full time per million people and employment rate were used in the analysis. This figure is normalized and transformed for the same reason as other variables. The original data of employment rate are used as it is approximately a normal distribution. Scientists and engineers are the most important human resources for innovation development, but they also need support from other staff with general administrative issues. This is why employment rate is also included.

For knowledge stock, GDP per capita ${ }^{2}$ and patent stock $^{3}$ are proposed as two indicators. GDP per capita captures the ability of a country or a region to bring about the economic value of its knowledge, ${ }^{4}$ while patent stock directly measures the national or regional pool of technology. As GDP per capita is strongly correlated with patent counts and patent counts are used as an independent variable in the analysis, only GDP per capita is included in our study. GDP per capita represents the economic infrastructure of a country or a region as well.

In sum, the institutional; environment as innovation input were measured by (INPUT1) GDP per person, (INPUT 2) Funding for science and technology activities per thousand GDP, (INPUT 3), full-time employed scientists and engineers per million persons and (INPUT 4) Employment rate.

\subsubsection{Interaction}

\footnotetext{
2 (Furman et al., 2002)

${ }^{3}$ Furman, Porter and Scott 2002; Zabala-Iturriagagoitia et al. 2007.

${ }^{4}$ (Xibao Li, 2009).
} 
Through interactions, innovation actors can learn from each, share knowledge and resources, and consequently accelerate the progress of innovation. With respect to domestic interactions, Li (2009) used the proportion of Science and Technology (S\&T) funds raised from firms by universities and research institutes to measure the interactions among firms, universities and research institutes and contract value in the regional technology market to measure interactive learning. These two measures together consider both financial capital flow and knowledge flow.

In view of knowledge, the value of domestic technology contracts in technology market is employed to measure the technological interactions between innovation actors. A strong technology market is important for technology transfer and utilisation of patents across regions, while the measure of technology contracts set by the State Science and Technology Commission captures activities of transforming patented technologies into commodities (Johnson \& Liu, 2011). Hence, technology contracts represent both knowledge flow and interactive learning between regions and within a region.

Beside domestic interactions, the development of RIS is becoming more dependent on external linkages. Technological knowledge from advanced countries is an important connection for China (Asheim \& Vang, 2006; Giuliani et al., 2005). Hence, international interactions are covered in the analysis as well. Regions can access foreign technology and knowledge through FDI, international trade and the mobility of human capital across borders and collaborations (Liang, 2008; Z. Liu, 2008; Peng \& Wang, 2000; Zhang \& Rogers, 2009). Domestic innovation actors can benefit both from foreign technology providers and users.

Other than FDI, international trade is another channel to reach advanced technologies and knowledge to improve innovation capacity of a country or a region. Technology traded with international innovation actors will increase the quality of goods (Spulber, 2008), as 
foreign users may facilitate exporters to improve their product to meet the criteria of foreign markets (Chuang \& Hsu, 2004; Lin \& Lin, 2010). Accordingly, both FDI and international trade may have direct and indirect impact on the development of innovation capacity in China. Therefore, the annual inflow of FDI and the sum of imports and exports were used to measure international interactions of a region.

In sum, the domestic and international interactions (DOMINTER) were measured by (DOMINTER 1) Inward foreign direct investment per thousand GDP, (DOMINTER 2) Import and export trade per thousand GDP and (DOMINTER 3) Value of Domestic technology contract per thousand GDP.

\subsubsection{Patents}

In our study, data are collected at the regional level. In terms of patent counts, regional means the location of the patent owner. Regional patent counts are the total number of patents applied for by, or granted to, the owners who are located in a specific region. A time $\operatorname{lag}^{5}$ between explanatory variables and patent data (output) is required in the models. It takes time to transform innovation effort to innovation capacity. In our study thus one year is taken as the average lag for applications and four years as the lag for all granted patents.

For applications, this study takes three years as the patent examination time, disregarding patent type. This amounts to four years lag between input and output for granted patents based on a recent study using patents filed at the Chinese State Intellectual Property

\footnotetext{
${ }^{5}$ To verify if the time lags give best fit, other time lags were checked by analyzing a dataset with a fixed time period for IVs and different time lags for DVs using the method of panel data analysis ${ }^{5}$. The results show for applications, zero, one year, and two year lags are equal best fit for the model, no matter which type of patent, as there are no big differences between $\mathrm{R}$ squares. There are slight differences between the effects of the same IV on different DVs. For granted patents, models with four and five year lags explain more variances than the others for all three DVs. Meanwhile the key results are robust in these two models. Therefore, considering both the verified results and what has been used in previous research, the time lags chosen here are appropriate and reasonable.
} 
Office findings. ${ }^{6}$ In sum, our study employed the number of (DV1) total patent applications (DV2), overall granted patents, (DV3) granted invention patents and (DV4) granted utility model patents per million people.

\subsubsection{Interactive effects}

Regarding the effect of FDI and international trade on RIC, absorptive capacity was frequently mentioned in the literature as one reason for the negative impact. ${ }^{7}$ It is found that absorptive capacity affects the impact of knowledge acquisition on innovation capacity at the firm level, industry level, as well as the national level (Anwar \& Nguyen, 2010; Fu \& Gong, 2011; Liao, Wu, Hu, \& Tsui, 2010). Researchers found R\&D efforts improve organisations' absorptive capacity (Xiaohui Liu \& Zou, 2008). R\&D investment is the commonly used proxy of absorptive capacity (Cohen \& Levinthal, 1990; Kostopoulos, Papalexandris, Papachroni, \& Ioannou, 2010; Lai, Peng, \& Bao, 2006). Hence, we can infer that S\&T investment, which is a broader measure of $\mathrm{R} \& \mathrm{D}$ effort, may influence the impact of interactions between innovation actors such as FDI, international trade, and domestic technology transfer.

It is found that absorptive capacity affects the impact of knowledge acquisition on innovation capacity at the firm level, industry level, as well as the national level (Anwar \& Nguyen, 2010; Fu \& Gong, 2011; Liao et al., 2010). Researchers found R\&D efforts improve organisations' absorptive capacity (Xiaohui Liu \& Zou, 2008). R\&D investment is the commonly used proxy of absorptive capacity (Cohen \& Levinthal, 1990; Kostopoulos et al., 2010; Lai et al., 2006). Hence, we can infer that S\&T investment, which is a broader measure of R\&D effort, may influence the impact of interactions between innovation actors such as FDI, international trade, and domestic technology transfer.

\footnotetext{
${ }^{6}$ (Wagner \& Liegsalz, 2011)

${ }^{7}$ (Cohen \& Levinthal, 1989; Fu \& Gong, 2011).
} 
$\mathrm{R} \& \mathrm{D}$ investment is widely used as the measure of absorptive capacity as it will enhance learning capability and the ability to exploit outside knowledge. ${ }^{8}$ Thus, our study will explore whether S\&T investment helps in benefiting from international and domestic interactions. Further, we examine whether S\&T investment influences the relationships between interactions and RIC at the regional level. Specifically, the interactive effects in our analysis were funding for INPUT 2 with DOMINTER 1 (MOD1); INPUT 2 with DOMINTER 2 (MOD2); INPUT 2 with DOMINTER 3 (MOD3) and DOMINTER 2 interacted with DOMINTER 3 (MOD4).

\subsection{Analyses}

First, our study thus employs the hierarchical cluster analysis to classify the regions based on its innovation level. The results ${ }^{9}$ of cluster analysis classified three groups, i.e. Group 1 represents the high innovation regions ${ }^{10}$, Group 2 are medium innovation regions ${ }^{11}$, and Group 3 consists of low innovation regions ${ }^{12}$. The high and medium innovation groups include regions from East China, while low innovation regions are mainly located in Central and West China.

\footnotetext{
${ }^{8}$ Hervas-Oliver, Garrigos and Gil-Pechuan 2011.

${ }^{9}$ Full results can be obtained from the authors

${ }^{10}$ Beijing, Shanghai, Tianjin

${ }^{11}$ Fujian, Guangdong, Jiangsu, Liaoning, Shandong, Zhejiang

${ }^{12}$ Anhui, Chongqing, Gansu, Guangxi, Guizhou, Hainan, Hebei, Heilongjiang, Henan, Hubei, Hunan, Jiangxi, Jilin, Neimenggu, Ningxia, Qinghai, Shaanxi, Shanxi, Sichuan, Xinjiang, Yunnan
} 
Table 1 displayed the descriptive statistics and number of cases.

\begin{tabular}{lcrrrrr}
\hline & G1 $(\mathrm{N}=45)$ & \multicolumn{2}{c}{$\mathrm{G} 2(\mathrm{~N}=90)$} & \multicolumn{2}{c}{$\mathrm{G} 3(\mathrm{~N}=315)$} \\
\hline & Mean & Std. Dev & Mean & Std. Dev & Mean & Std. Dev \\
\hline DV1 & 2.688 & .355 & 2.191 & .345 & 1.663 & .253 \\
DV2 & 2.546 & .366 & 2.165 & .426 & 1.544 & .302 \\
DV3 & 1.622 & .614 & .771 & .609 & .430 & .514 \\
DV4 & 2.292 & .284 & 1.845 & .349 & 1.327 & .287 \\
ACTOR1 & 3.468 & .155 & 2.919 & .182 & 2.929 & .178 \\
ACTOR2 & 1.778 & .159 & 1.405 & .190 & 1.061 & .140 \\
INPUT1 & 4.216 & .292 & 3.943 & .282 & 3.627 & .273 \\
INPUT2 & 1.739 & .246 & 1.154 & .226 & 1.126 & .251 \\
INPUT3 & 3.884 & .199 & 3.124 & .242 & 2.959 & .209 \\
INPUT4 & .535 & .040 & .550 & .059 & .505 & .058 \\
DOMINTER1 & 1.846 & .272 & 1.715 & .308 & 1.106 & .474 \\
DOMINTER2 & 2.970 & .235 & 2.629 & .292 & 1.970 & .215 \\
DOMINTER3 & 1.287 & .339 & .564 & .270 & .449 & .448 \\
\hline
\end{tabular}

Note:

Overall patent applications (DV1), overall granted patents (DV2) granted invention patents (DV3) and granted utility model patents (DV4).

(ACTOR1) No. of HEIs; (ACTOR2) No. of large and medium-sized industrial enterprises; (INPUT1) GDP; (INPUT 2) Funding for S\&T, (INPUT 3); full-time employed scientists and engineers; (INPUT 4) Employment rate; (DOMINTER 1) Inward FDI; (DOMINTER 2) Import and export trade; (DOMINTER 3) Value of Domestic technology contract.

$\mathrm{G} 1=$ high innovation regions; $\mathrm{G} 2=$ medium innovation regions; $\mathrm{G} 3=$ low innovation regions

Second, we employ Generalized least squares regressions with fixed effect to explore the impact of RIC determinants (actors, inputs and interaction) across three groups, which is our focal study. This approaches give the maximum likelihood estimate due to heteroscedasticity (i.e the innovation level is unequal across three groups). Further, a fixed effect model has several advantages over a random effect model in the context of this study. In the case of this research, the most important consideration is the random effect model is appropriate if the sample is randomly drawn from a large population, and the fixed effect model is more suitable for a specific set of units (Baltagi, 2008). The units used here are not randomly sampled, they are the specific 30 regions in China (it is almost the population of 
China, except Tibet). This approach rules out the appropriateness of random effect model at the first instance. The results are discussed in the following section. Figure 1 displays the proposed model for our analyses.

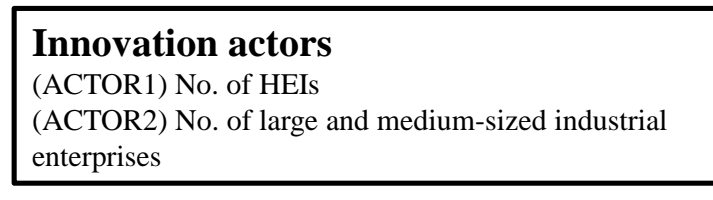

\section{Innovation inputs}

(INPUT1) GDP

(INPUT 2) Funding for S\&T

(INPUT 3); full-time employed scientists and engineers

(INPUT 4) Employment rate

Interactions (domestic \& international)

(DOMINTER 1) Inward FDI

(DOMINTER 2) Import and export trade (DOMINTER

3) Value of Domestic technology contract

\section{Innovation activity}

overall patent applications (DV1)

overall granted patents (DV2)

granted invention patents (DV3)

granted utility model patents (DV4)

\section{Inputs $x$ Integrations \\ (MOD1) INPUT $2 \times$ DOMINTER 1 \\ (MOD2) INPUT 2 x DOMINTER 2 (MOD3)INPUT $2 x$ \\ DOMINTER 3 \\ (MOD4) DOMINTER 2 x DOMINTER 3.}

Figure 1: A propose model for our analyses

\section{Results}

The impact of innovation actors, innovation input and domestic and international interaction on overall applications and granted patents are listed in Table 2. The results showed that number of higher education institutions (ACTOR1) and number of large and medium-sized enterprises (ACTOR2) positively impacted on overall application (DV1) only for medium innovation regions (G2) and low innovation regions (G3).

On the other hand, GDP per capita (INPUT1) positively impacted on overall application (DV1) and overall granted patents (DV2) across three regions. Funding for scientific and technological activities (INPUT2) positively impacted on overall application 
(DV1) only for high innovation regions (G1) and medium innovation regions (G2). Full time employed scientists and engineers (INPUT3) and employment rate (INPUT4) positively impacted on overall application (DV3) and overall granted patents (DV2) only for low innovation regions (G3). However, the negative relationships were shown between INPUT3 and DV1 for high innovation regions (G1) and INPUT4 and DV1 for medium innovation regions (G2).

The impact of FDI (DOMINTER1) negatively influenced on overall application (DV1) across three regions. However, DOMINTER1 negatively impacted on DV2 only for high innovation regions (G1) and low innovation regions (G3). The impact of import and export (DOMINTER2) positively influenced on overall application (DV1) across three regions. However, DOMINTER2 positively impacted on DV2 only for high innovation regions (G1) and low innovation regions (G3). Value of domestic technology contract (DOMINTER3) only showed a positive impact on overall application (DV1) across three regions. 
Table 2 Main effects of innovation actors, innovation inputs and interaction on overall patent applications (DV1) and overall granted patents (DV2) across three regional groups (G1=high innovation regions; $\mathrm{G} 2=$ medium innovation regions; $\mathrm{G} 3=$ low innovation regions)

\begin{tabular}{|c|c|c|c|c|c|c|}
\hline & \multicolumn{3}{|c|}{ Overall patent applications (DV1) } & \multicolumn{3}{|c|}{ Overall granted patents (DV 2) } \\
\hline & G1 & G2 & G3 & G1 & G2 & G3 \\
\hline \multirow[t]{2}{*}{ ACTOR1 } & .002 & $.200 * *$ & $.159 *$ & .003 & -.145 & 111 \\
\hline & $(.182)$ & $(.093)$ & $(.095)$ & $(.262)$ & $(.238)$ & $(.123)$ \\
\hline \multirow{2}{*}{ ACTOR 2} & -.027 & -.067 & -.099 & -.198 & -.286 & -.156 \\
\hline & $(.243)$ & (.069) & $(.083)$ & (.349) & (.179) & (.107) \\
\hline \multirow[t]{2}{*}{ INPUT1 } & $.868 * * *$ & $.835 * * *$ & $.564 * * *$ & $.931 * * *$ & $1.252 * * *$ & $.872 * * *$ \\
\hline & $(.119)$ & $(.066)$ & $(.044)$ & $(.171)$ & $(.171)$ & $(.057)$ \\
\hline \multirow{2}{*}{ INPUT 2} & $.828 * *$ & $.322 * * *$ & .078 & -.175 & .300 & -.048 \\
\hline & $(.322)$ & (.114) & (.057) & $(.462)$ & $(.293)$ & $(.073)$ \\
\hline \multirow[t]{2}{*}{ INPUT 3} & $-1.052 * *$ & 163 & $211^{* *}$ & -1.081 & 230 & $.226^{*}$ \\
\hline & $(.460)$ & $(.142)$ & $(.097)$ & $(.660)$ & $(.366)$ & $(.125)$ \\
\hline \multirow[t]{2}{*}{ INPUT 4} & -.086 & $-.702 * *$ & $.510^{*}$ & -1.167 & -.767 & $.787 * *$ \\
\hline & $(.583)$ & (.298) & $(.262)$ & $(.837)$ & $(.768)$ & $(.338)$ \\
\hline \multirow[t]{2}{*}{ DOMINTER1 } & $-.441 * * *$ & $-.225^{* * *}$ & $-.112 * * *$ & $-.423 * * *$ & -.086 & $-.059 * *$ \\
\hline & $(.073)$ & $(.048)$ & $(.022)$ & $(.105)$ & $(.124)$ & $(.028)$ \\
\hline \multirow[t]{2}{*}{ DOMINTER 2} & $.617 * * *$ & $.325 * * *$ & $.101 *$ & $.747 * * *$ & .167 & $.278 * * *$ \\
\hline & $(.118)$ & (.079) & $(.053)$ & (.169) & (.203) & $(.068)$ \\
\hline \multirow[t]{2}{*}{ DOMINTER 3} & $.212 * * *$ & $-.122 * *$ & $.046^{* *}$ & .062 & .116 & .003 \\
\hline & $(.077)$ & $(.053)$ & $(.021)$ & $(.110)$ & $(.137)$ & $(.028)$ \\
\hline \multirow[t]{2}{*}{ _cons } & .470 & $-2.487 * * *$ & $-1.807 * * *$ & 2.719 & $-2.823 * * *$ & $-3.186 * * *$ \\
\hline & (1.453) & $(.235)$. & $(.252)$ & (2.086) & (.605) & $(.326)$ \\
\hline Within R-sq & 9365 & 9605 & .7544 & .8919 & .8553 & .7887 \\
\hline
\end{tabular}

Note:

Standard errors are in the parentheses, ${ }^{* * *} \mathrm{p}<0.01,{ }^{* *} \mathrm{p}<0.05,{ }^{*} \mathrm{p}<0.1$

(ACTOR1) No. of HEIs per billion people; (ACTOR2) No. of large and medium-sized industrial enterprises per million people; (INPUT1) GDP per person; (INPUT 2) Funding for S\&T per thousand GDP, (INPUT 3); fulltime employed scientists and engineers per million persons; (INPUT 4) Employment rate; (DOMINTER 1) Inward FDI per thousand GDP; (DOMINTER 2) Import and export trade per thousand GDP; (DOMINTER 3) Value of Domestic technology contract per thousand GDP 
The impact of innovation actors, innovation input and domestic and international interaction on granted invention patents and granted utility model patents are listed in Table 3. The results showed that number of higher education institutions (ACTOR1) negatively influenced only on granted invention patents (DV3) for low innovation regions (G3) and on low innovation regions (G3) for high innovation regions (G1). The number of large and medium-sized enterprises (ACTOR2) negatively impacted only on granted invention patents (DV3) and only for medium innovation regions (G2) and low innovation regions (G3).

On the other hand, GDP per capita (INPUT1) positively impacted on granted invention patents (DV3) and granted utility model patents (DV4) across three regions. Funding for scientific and technological activities (INPUT2) positively impacted only on granted invention patents (DV3) and only for high innovation regions (G1) and low innovation regions (G3). Full time employed scientists and engineers (INPUT3) positively impacted on granted invention patents (DV3) only for medium innovation regions (G2) and low innovation regions (G3). However, there were negatively relationship between INPUT3 and DV3 on G1 and INPUT3 and DV3 on G1. Employment rate (INPUT4) impacted only on granted invention patents (DV3), showing negative relationship for G1 and G2, but positive relationship for $\mathrm{G} 3$.

The impact of FDI (DOMINTER1) negatively influenced on granted invention patents (DV3) and granted utility model patents (DV4) across three regions. The impact of import and export (DOMINTER2) positively influenced on granted utility model patents (DV4) across three regions and on granted invention patents (DV3) only for high innovation regions (G1) and medium innovation regions (G2). However, DOMINTER2 negatively impacted on DV3 only for low innovation regions (G3). Value of domestic technology 
contract (DOMINTER3) only showed a positive impact on granted invention patents (DV3) only for G1 and G3, and on granted utility model patents (DV4) only for G1.

Table 3 Main effects of innovation actors, innovation inputs and interaction on Granted invention patents (DV3) and Granted utility model patents (DV4) across three regional groups $(\mathrm{G} 1=$ high innovation regions; $\mathrm{G} 2=$ medium innovation regions; $\mathrm{G} 3=$ low innovation regions)

\begin{tabular}{|c|c|c|c|c|c|c|}
\hline & \multicolumn{3}{|c|}{ Granted invention patents (DV3) } & \multicolumn{3}{|c|}{ Granted utility model patents (DV 4) } \\
\hline & G1 & G2 & G3 & G1 & G2 & G3 \\
\hline \multirow[t]{2}{*}{ ACTOR1 } & -.278 & .833 & $-1.582 * * *$ & $-.267 *$ & .100 & $.455 * * *$ \\
\hline & (.693) & $(.510)$ & $(.511)$ & (.143) & (.135) & $(.120)$ \\
\hline \multirow[t]{2}{*}{ ACTOR 2} & -.255 & $-.739 *$ & $-1.405 * * *$ & -.276 & .122 & -.112 \\
\hline & $(.924)$ & $(.382)$ & $(.445)$ & $(.192)$ & $(.101)$ & $(.104)$ \\
\hline \multirow[t]{2}{*}{ INPUT1 } & $5.335 * * *$ & $4.948 * * *$ & $5.507 * * *$ & $.979 * * *$ & $1.054 * * *$ & $.726 * * *$ \\
\hline & (.454) & (.366) & $(.238)$ & (.094) & (.097) & $(.056)$ \\
\hline \multirow[t]{2}{*}{ INPUT 2} & $3.182 * *$ & .869 & $1.350 * * *$ & .256 & .142 & .032 \\
\hline & $(1.223)$ & (.627) & $(.305)$ & $(.254)$ & $(.133)$ & $(.071)$ \\
\hline \multirow[t]{2}{*}{ INPUT 3} & $-4.285^{* *}$ & $2.181 * * *$ & $1.378 * * *$ & $-1.325^{* * *}$ & .323 & .122 \\
\hline & $(1.748)$ & (.784) & $(.517)$ & $(.353)$ & $(.208)$ & $(.121)$ \\
\hline \multirow[t]{2}{*}{ INPUT 4} & $-5.648 * *$ & $-5.174 * * *$ & $3.741 * * *$ & .610 & -.449 & .500 \\
\hline & $(2.216)$ & (10643) & $(1.405)$ & $(.460)$ & (.435) & $(.329)$ \\
\hline \multirow[t]{2}{*}{ DOMINTER1 } & $-1.384 * * *$ & $-1.470 * * *$ & $-.524 * * *$ & $-.388 * * *$ & $-.259 * * *$ & $-.131 * * *$ \\
\hline & $(.277)$ & $(.265)$ & $(.116)$ & $(.058)$ & $(.070)$ & $(.027)$ \\
\hline \multirow[t]{2}{*}{ DOMINTER 2} & $1.430 * * *$ & $.741 *$ & $-1.211 * * *$ & $.761 * * *$ & $.377 * * *$ & $.309 * * *$ \\
\hline & (.449) & (.435) & $(.282)$ & $(.093)$ & (.115) & $(.066)$ \\
\hline \multirow[t]{2}{*}{ DOMINTER 3} & $.731 * *$ & -.411 & $.297 * *$ & $.106^{*}$ & -.087 & -.031 \\
\hline & $(.292)$ & (.294) & $(.115)$ & $(.061)$ & $(.078)$ & $(.027)$ \\
\hline \multirow[t]{2}{*}{ _cons } & -4.661 & $-22.739 * * *$ & $-17.203 * * *$ & $2.791 * *$ & $-3.785 * * *$ & $-3.316 * * *$ \\
\hline & $(5.523)$ & (1.295) & (1.353) & (1.148) & (.343) & $(.317)$ \\
\hline Within R-sq & .9671 & .9619 & .8678 & .9563 & .9471 & .7801 \\
\hline
\end{tabular}

Note:

Standard errors are in the parentheses, ${ }^{* * *} \mathrm{p}<0.01,{ }^{*} \mathrm{p}<0.05,{ }^{*} \mathrm{p}<0.1$

(ACTOR1) No. of HEIs per billion people; (ACTOR2) No. of large and medium-sized industrial enterprises per million people; (INPUT1) GDP per person; (INPUT 2) Funding for S\&T per thousand GDP, (INPUT 3); fulltime employed scientists and engineers per million persons; (INPUT 4) Employment rate; (DOMINTER 1) Inward FDI per thousand GDP; (DOMINTER 2) Import and export trade per thousand GDP; (DOMINTER 3) Value of Domestic technology contract per thousand GDP 
The interactive effects between S\&T effort and interactions and international and domestic interactions are shown in Table 4 (for DV1 \& DV2) and Table 5 (for DV 3 \& DV 4). The interactive effect MOD1 [between (INPUT 2) funding for S\&T and (DOMINTER 1) inward FDI] negatively impacted only on overall applications (DV1) for medium innovation regions (G2) and only on granted invention patents (DV3) for low innovation regions (G3).

The interactive effect MOD2 [between (INPUT 2) funding for S\&T and (DOMINTER 2) import and export trade] positively impacted on overall patent applications (DV1) and overall granted patents (DV2) only for high innovation regions (G1). Further, MOD2 positively influenced on granted invention patents (DV3) only for medium innovation regions (G2) and granted utility model patents (DV4) only for low innovation regions (G3).

The interactive effect MOD3 [between (INPUT 2) funding for S\&T and (DOMINTER 3) value of Domestic technology contract] negatively impacted across four types of patents (DV1-DV4) but only for low innovation regions (G3). Further, MOD3 has a positive effect on overall applications (DV1) and granted utility model patents (DV4) only for medium innovation regions $(\mathrm{G} 2)$.

The interactive effect MOD3 [between (DOMINTER 2) import and export trade and (DOMINTER 3) value of Domestic technology contract] positively impacted on overall granted patents (DV2) and granted utility model patents (DV4) only for low innovation regions (G3). Further, MOD3 negatively impacted on granted invention patents (DV3) only for low innovation regions (G3). 
Table 4 Interactive effects of innovation actors, innovation inputs and interaction on overall patent applications (DV1) and overall granted patents (DV2) across three regional groups (G1=high innovation regions; G2=medium innovation regions; $\mathrm{G} 3=$ low innovation regions)

\begin{tabular}{|c|c|c|c|c|c|c|}
\hline & \multicolumn{3}{|c|}{ Overall applications (DV1) } & \multicolumn{3}{|c|}{ Overall granted patents (DV 2) } \\
\hline & G1 & G2 & G3 & G1 & G2 & G3 \\
\hline \multirow[t]{2}{*}{ MOD1 } & .505 & $-.430 * * *$ & -.063 & .634 & -.470 & -.042 \\
\hline & $(.419)$ & $(.142)$ & $(.064)$ & $(.608)$ & $(.385)$ & $(.083)$ \\
\hline \multirow[t]{2}{*}{ MOD2 } & $1.587 * *$ & .294 & -.124 & $2.317^{* *}$ & .301 & -.262 \\
\hline & $(.676)$ & $(.195)$ & $(.148)$ & $(.964)$ & $(.508)$ & $(.190)$ \\
\hline \multirow[t]{2}{*}{ MOD3 } & -.048 & $.773 * * *$ & $-.209 * *$ & .512 & -.439 & $-.534 * * *$ \\
\hline & $(.418)$ & $(.214)$ & $(.081)$ & $(.593)$ & $(.595)$ & $(.097)$ \\
\hline \multirow[t]{2}{*}{ MOD4 } & -.209 & -.143 & -.020 & -.025 & -.176 & $.073^{*}$ \\
\hline & $(.309)$ & $(.132)$ & $(.030)$ & $(.447)$ & $(.342)$ & $(.037)$ \\
\hline \multirow{2}{*}{ _cons } & .636 & $-2.913 * * *$ & $-1.814 * * *$ & 2.113 & $-2.868 * * *$ & $-2.800 * * *$ \\
\hline & $(1.817)$ & $(.252)$ & $(.264)$ & (2.631) & (.654) & $(.327)$ \\
\hline Within R-sq & .9372 & .9614 & .7520 & .8913 & .8557 & .8033 \\
\hline
\end{tabular}

Table 5 Interactive effects of innovation actors, innovation inputs and interaction on Granted invention patents (DV3) and Granted utility model patents (DV4) across three regional groups $(\mathrm{G} 1=$ high innovation regions; $\mathrm{G} 2=$ medium innovation regions; $\mathrm{G} 3=$ low innovation regions)

\begin{tabular}{|c|c|c|c|c|c|c|}
\hline & \multicolumn{3}{|c|}{ Granted invention patents (DV3) } & \multicolumn{3}{|c|}{ Granted utility model patents (DV 4) } \\
\hline & G1 & G2 & G3 & G1 & G2 & G3 \\
\hline \multirow[t]{2}{*}{ MOD1 } & 2.087 & .031 & $1.032 * * *$ & .155 & -.196 & .095 \\
\hline & $(1.582)$ & $(.831)$ & $(.340)$ & $(.339)$ & $(.218)$ & $(.081)$ \\
\hline \multirow{2}{*}{ MOD2 } & .854 & $2.781 * * *$ & .647 & .707 & .401 & $.316^{*}$ \\
\hline & $(2.755)$ & $(1.042)$ & $(.792)$ & $(.564)$ & $(.285)$ & $(.185)$ \\
\hline \multirow[t]{2}{*}{ MOD3 } & -.104 & .538 & $-.799 *$ & -.217 & $.692 * *$ & $-.621 * * *$ \\
\hline & $(1.580)$ & $(1.276)$ & (.415) & $(.327)$ & $(.329)$ & (.086) \\
\hline \multirow{2}{*}{ MOD4 } & .876 & .771 & $-.292 * *$ & -.215 & .145 & $.068^{* *}$ \\
\hline & $(1.168)$ & $(.727)$ & $(.151)$ & $(.243)$ & (.193) & $(.034)$ \\
\hline \multirow[t]{2}{*}{ _cons } & -9.190 & $-25.654 * * *$ & $-15.164 * * *$ & $2.941 * *$ & $-4.311 * * *$ & $-2.729 * * *$ \\
\hline & $(6.878)$ & $(1.390)$ & (1.337) & $(1.430)$ & (.369) & $(.299)$ \\
\hline Within R-sq & .9678 & .9625 & .8816 & .9571 & .9478 & .8202 \\
\hline
\end{tabular}

Note:

Standard errors are in the parentheses, $* * * \mathrm{p}<0.01, * * \mathrm{p}<0.05, * \mathrm{p}<0.1$

(MOD1) INPUT 2 x DOMINTER 1; (MOD2) INPUT 2 x DOMINTER 2; (MOD3)INPUT 2 x DOMINTER 3; (MOD4) DOMINTER 2 x DOMINTER 3.

(ACTOR1) No. of HEIs per billion people; (ACTOR2) No. of large and medium-sized industrial enterprises per million people; (INPUT1) GDP per person; (INPUT 2) Funding for S\&T per thousand GDP, (INPUT 3); fulltime employed scientists and engineers per million persons; (INPUT 4) Employment rate; (DOMINTER 1) Inward FDI per thousand GDP; (DOMINTER 2) Import and export trade per thousand GDP; (DOMINTER 3) Value of Domestic technology contract per thousand GDP 
Simple slope analysis confirmed the significance of interactive effects found above. Figure 1 and Figure 2 show both low and high S\&T effort exacerbated the negative effect of FDI on overall applications in Group 2 and on granted invention patents in Group 3. The impact was greater in Group 3 than in Group 2. The results suggest increasing investment in S\&T does assist in benefiting from FDI, and even has the opposite effect.

The simple slope analysis also showed both low and high S\&T effort enhanced the positive effect of international trade on overall applications (Figure 3) and granted patents (Figure 4) in Group 1, on granted invention patents in Group 2 (Figure 5), and on granted utility model patents in Group 3 (Figure 6). From all these figures it can be seen the influence of increasing investment in S\&T was greater than decreasing the same amount of investment in S\&T. The influence was greater in high and medium innovation regions than in low innovation regions. It seems the more innovation the regions is, the more benefit it will get from international trade.

Figure 7 and Figure 8 showed high funding for S\&T buffered the negative effect of domestic technology transfer, both on overall applications and granted utility model patents. Meanwhile low S\&T effort exacerbated the negative effect of domestic technology. The results indicate S\&T effort moderates the relationship between domestic technology transfer and RIC positively in medium innovation regions.

Figure 9 to Figure 10 showed both high and low S\&T efforts enhanced the positive effect of domestic technology transfer on overall applications, overall granted patents, and granted invention patents. Figure 12 shows both high and low S\&T efforts buffered the negative effect of domestic technology transfer on granted utility model patents. The figures also indicate the effect of reducing S\&T effort is greater than increasing S\&T effort. Overall, 
S\&T effort plays a positive role in the relationship between domestic technology transfer and RIC in low innovation regions.

Figure 13 to Figure 15 showed both low and high FDI enhanced the positive effect of domestic technology transfer on overall granted patents and granted invention patents. In Group 3 both an increase and decrease of FDI buffered the negative effect on domestic technology transfer on granted utility model patents. When considering domestic technology transfer as a moderator (see Figure 16, Figure 17, and Figure 18), both an increase and decrease of domestic technology transfer exacerbated the negative impact of FDI, which means domestic technology transfer does not help low innovation regions to benefit from FDI. 
Figure 1 Interactive effects between funding for S\&T and FDI on overall applications in Group 2

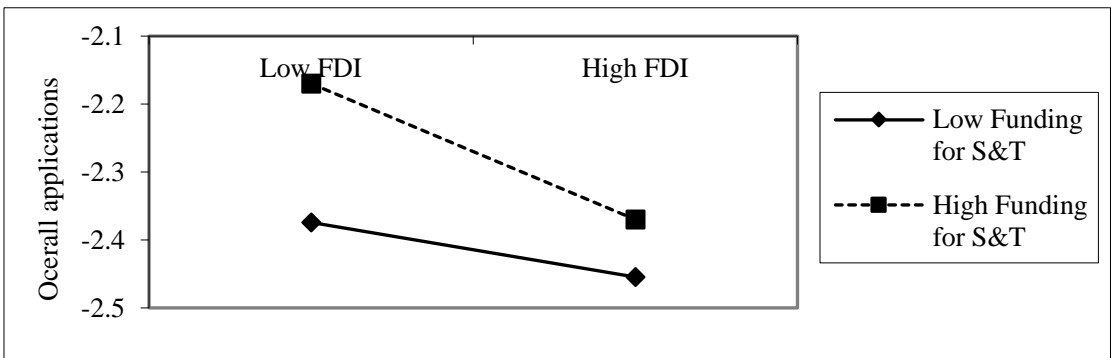

Figure 2 Interactive effects between funding for S\&T and FDI on granted invention patents in Group 3

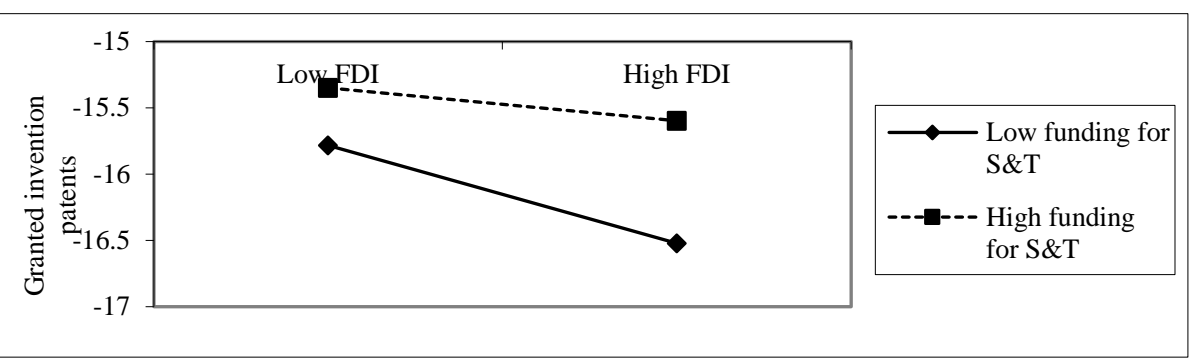

Figure 3 Interactive effects between funding for S\&T and international trade on overall applications in Group 1

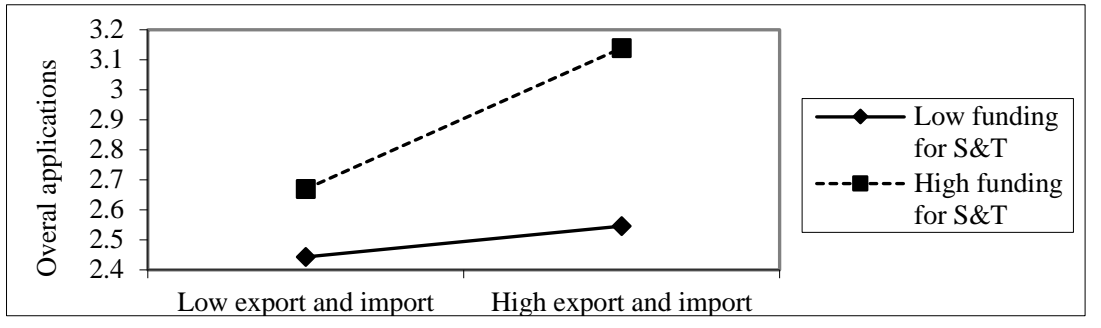

Figure 4 Interactive effects between funding for S\&T and international trade on overall granted patents in Group 1

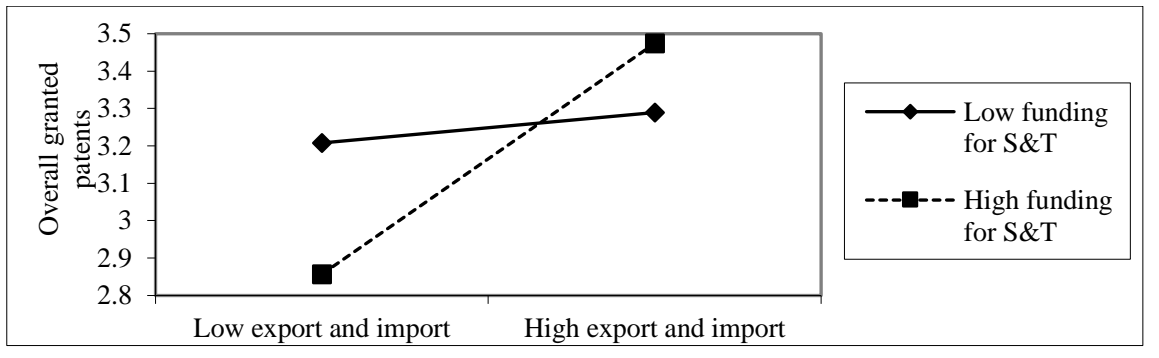


Figure 5 Interactive effects between funding for S\&T and international trade on granted invention patents in Group 2

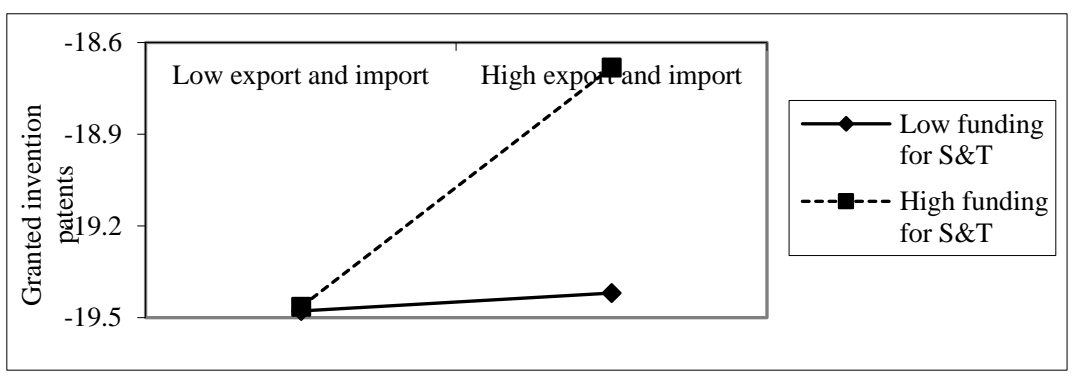

Figure 6 Interactive effects between funding for S\&T and international trade on granted utility model patents in Group 3

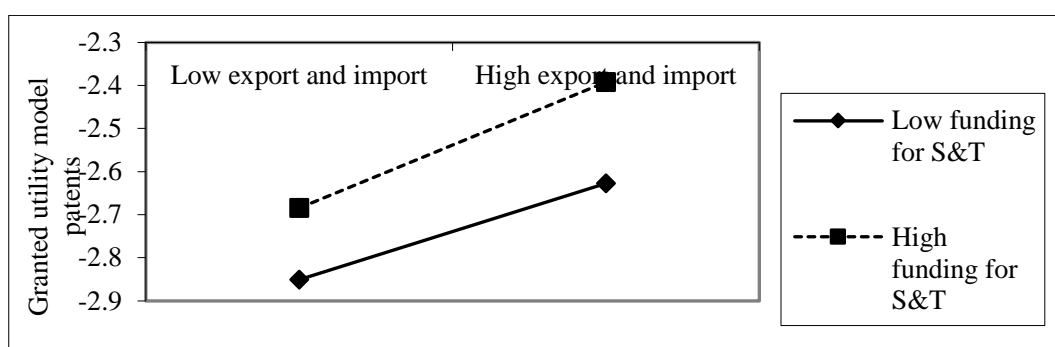

Figure 7 Interactive effects between funding for S\&T and domestic technology transfer on overall applications in Group 2

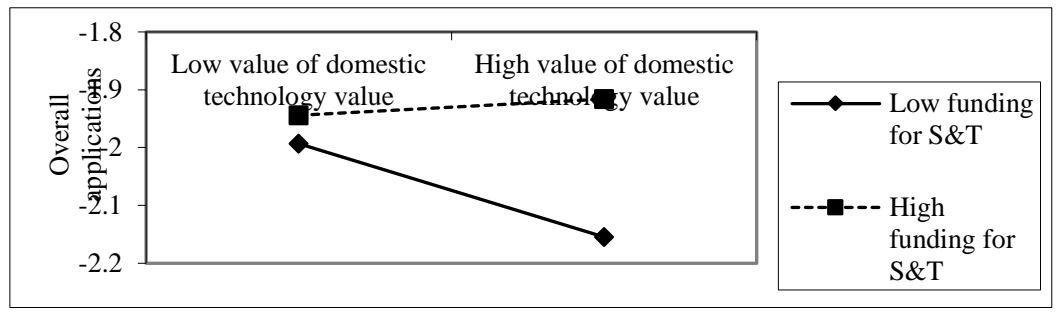

Figure 8 Interactive effects between funding for $S \& T$ and domestic technology transfer on granted utility model patents in Group 2

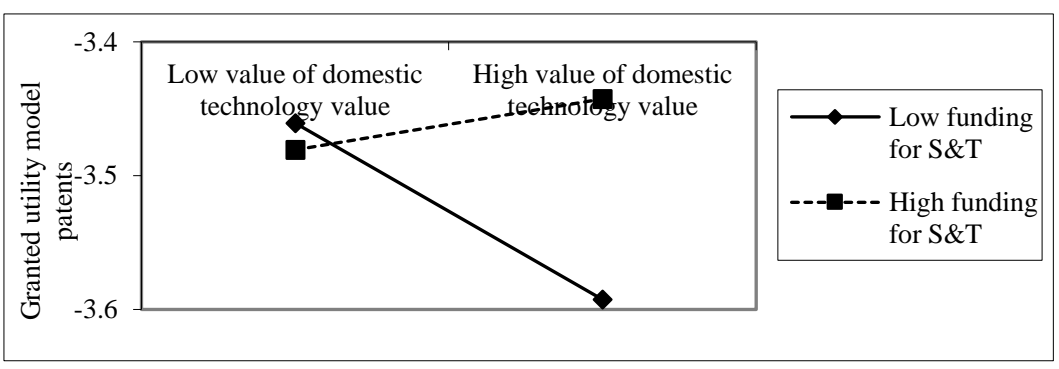


Figure 9 Interactive effects between funding for S\&T and domestic technology transfer on overall applications in Group 3

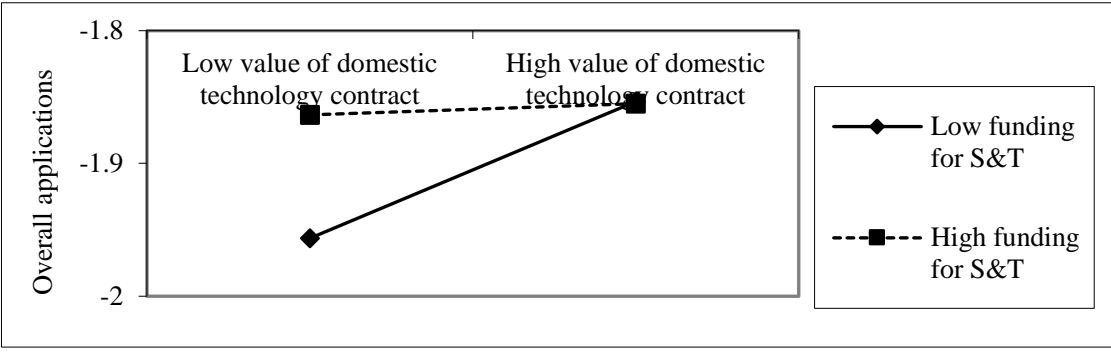

Figure 10 Interactive effects between funding for S\&T and domestic technology transfer on overall granted patents in Group 3

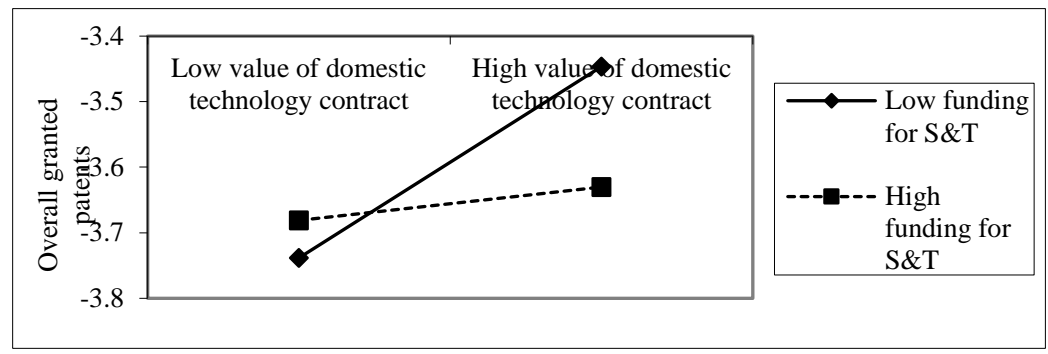

Figure 11 Interactive effects between funding for S\&T and domestic technology transfer on granted invention patents in Group 3

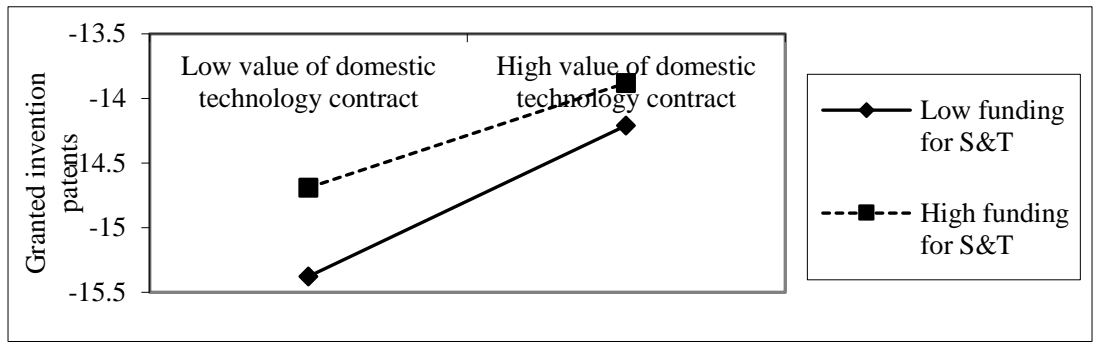

Figure 12 Interactive effects between funding for S\&T and domestic technology transfer on granted utility model patents in Group 3

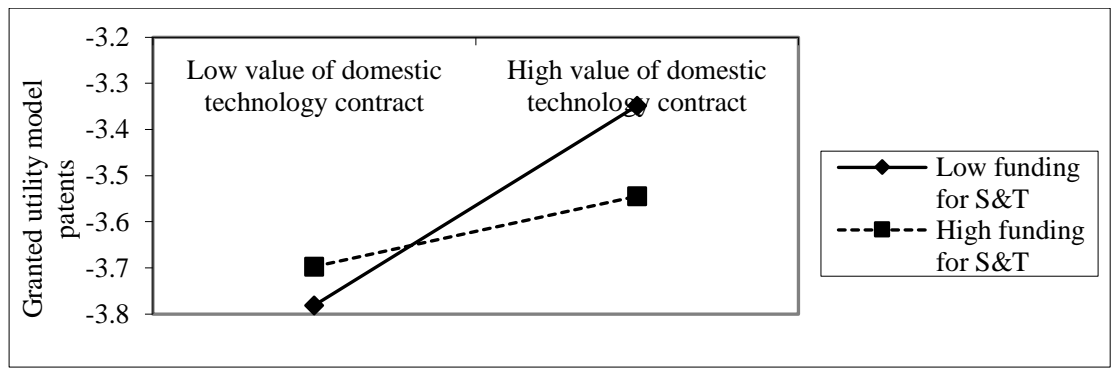


Figure 13 Interactive effects between FDI and domestic technology transfer on overall granted patents in Group 3 - FDI as the moderator

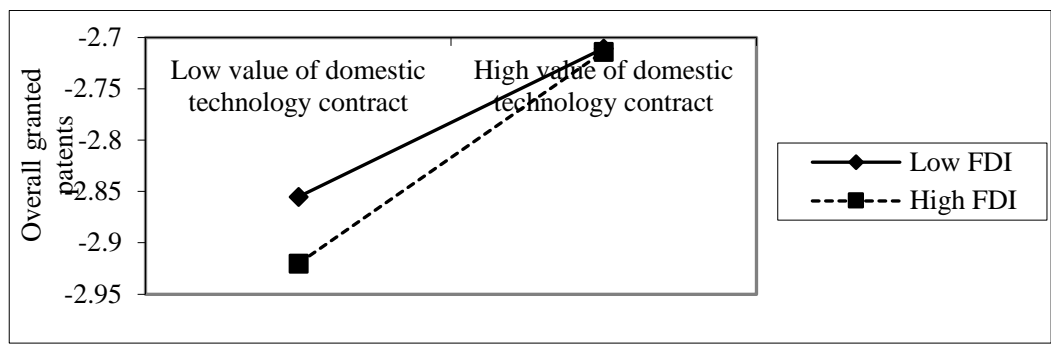

Figure 14 Interactive effects between FDI and domestic technology transfer on granted invention patents in Group 3 -- - FDI as the moderator

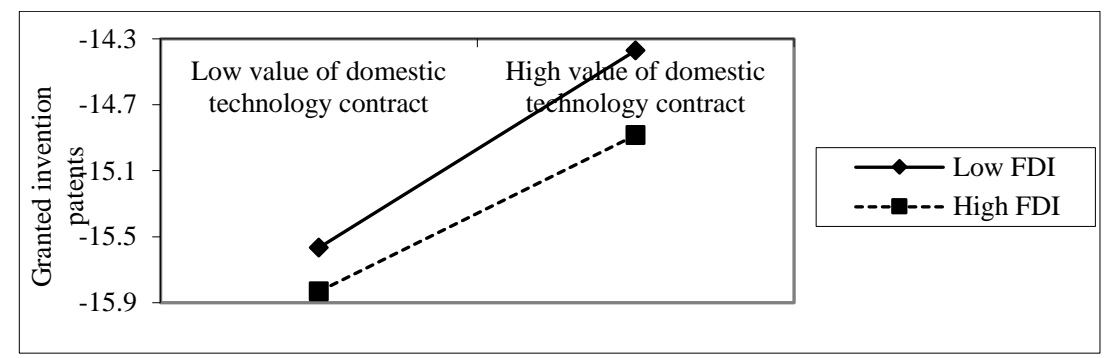

Figure 15 Interactive effects between FDI and domestic technology transfer on granted utility model patents in Group 3 -- - FDI as the moderator

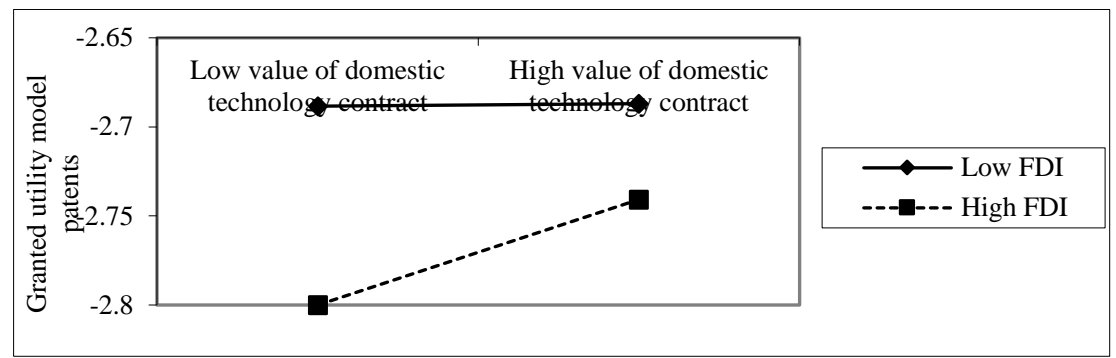

Figure 16 Interactive effects between FDI and domestic technology transfer on overall granted patents in Group 3-domestic technology transfer as the moderator

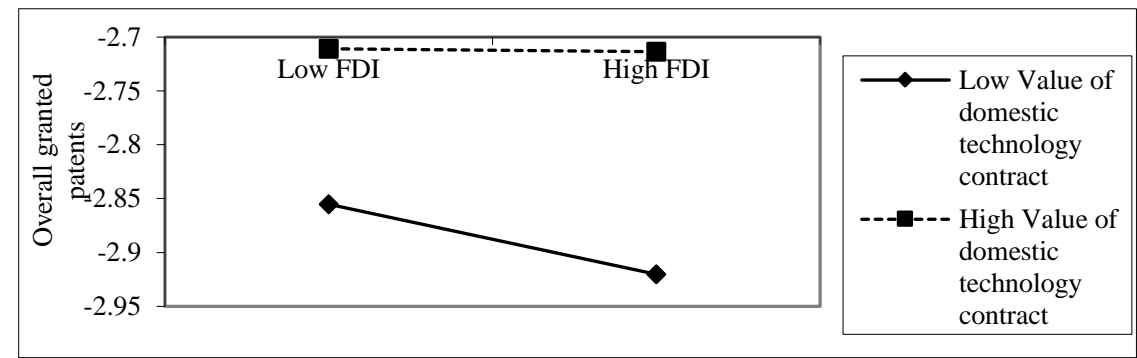


Figure 17 Interactive effects between FDI and domestic technology transfer on granted invention patents in Group 3 -- - domestic technology transfer as the moderator

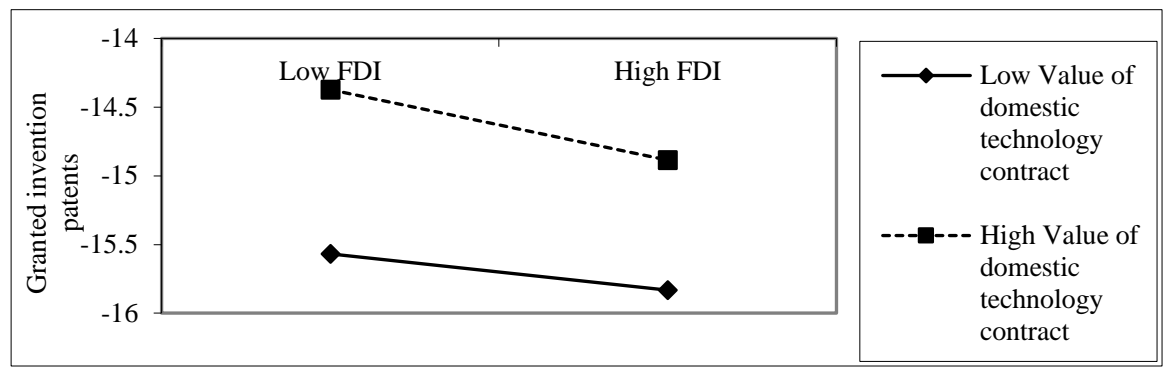

Figure 18 Interactive effects between FDI and domestic technology transfer on granted utility model patents in Group 3 -- - domestic technology transfer as the moderator

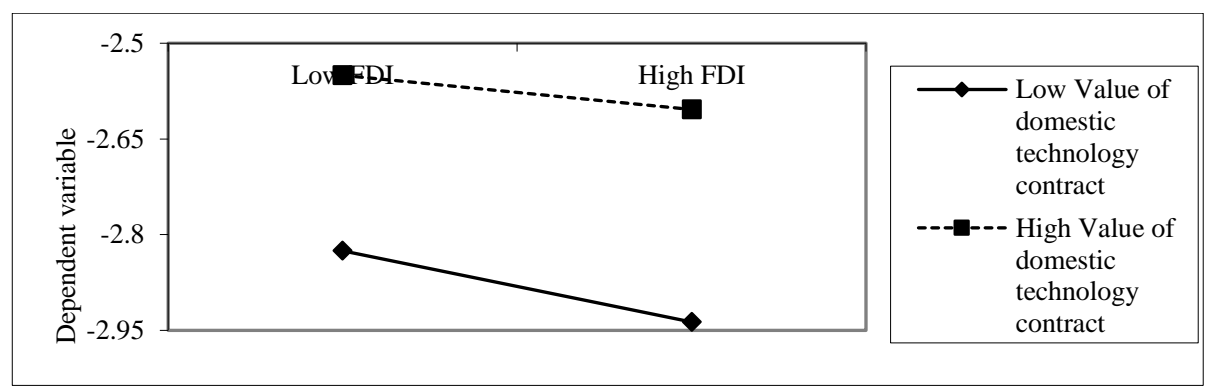

\section{Discussion}

\subsection{The impact of innovation actors}

FDI: The impact of FDI was negative on all four DVs across the three groups. It was only insignificant on overall granted patents in Group 2, which was consistent with the results found in overall regions. The negative impact of FDI was greater in Group 1 than in Group 2, and greater in Group 2 than in Group 3. This means the more innovative the region, the greater the negative impact of FDI, especially for incremental innovations. This finding may not be surprise because the effects of FDI on economic and innovation development in the innovation literature also show mixed results. There is evidence supporting both positive (Buckley, Clegg, \& Wang, 2002; Chuang \& Hsu, 2004; Hanousek, Kocenda, \& Maurel, 2011; Xiaoying Li, Liu, \& Parker, 2001; Xiaohui Liu \& Wang, 2003; Tian, 2007) and negative effects (A. G. Hu \& Jefferson, 2002; A. G. Hu, Jefferson, \& Qian, 2005; J.-T. Huang, 2004; 
Z. Liu, 2002), as well as no significant effect (J. Chen, Chen, \& Yu, 2007). The significant negative impact of FDI on patenting implies FDI brings pressure to bear on domestic organisations and the competitiveness of Foreign Invested Enterprise ${ }^{13}$ may crowd low capacity organisations out of the market (Fu \& Gong, 2011; Zhang \& Rogers, 2009), as the loss of market share may lower the incentives of domestic organisations to innovate (Jiang \& Xia, 2005). The negative impact also indicates increasing FDI alone will not improve the innovation capacity of a region. Policy makers should consider the conditions of benefiting from positive spillovers, as well as the way this may lead to a negative effect in order to make the best use of FDI for enhancing RIC.

Import and export: The impact of international trade in Group 1 and Group 2 was similar, but it was different from the impact in overall regions. The coefficients were positive and significant on all DVs in these two groups, except on overall granted patents in Group 2. The impact was greater in Group 1 than in Group 2 on the same DVs. In Group 3 the impact was quite similar to the overall regions. It was significantly positive on overall applications, overall granted patents, and granted utility model patents, but was significantly negative on granted invention patents. Regardless of the insignificant impact on overall granted patents in Group 2 and the negative impact on granted invention patents in Group 3, the impact on Group 2 was greater than on Group 3 on the same DVs. Hence, to some degree, the more innovative the region, the greater the positive impact of international trade on RIC would be.

Similar to the impact of FDI, evidence showed the more import and export trade takes up in GDP, the greater the positive effect will be. From 1991 to 2005 the average level of import and export was around 93.3 per cent of GDP in Group 1, 42.6 per cent in Group 2, and 9.3

\footnotetext{
${ }^{13}$ In China, any one of a number of legal entities can be considered FIEs including equity joint ventures (EJV), cooperative joint ventures (CJV), wholly-owned foreign enterprises (WFOE) and foreign-invested companies limited by shares (FCLS).
} 
percent in Group 3. Therefore, the results suggest the impact of FDI and international trade relates to the ratio of FDI and international trade that takes in regional GDP.

Value of domestic technology contract: Consistent with Zhao and his colleagues' (2011) findings, the results from this study indicate technology transfer has different impacts in regions at different innovation levels. In Group 1, the effect was positive and significant on overall applications and the two categories of granted patents. In Group 2 the impact was only negatively significant on overall applications. However, in Group 3 the impact on overall applications and granted invention patents became positive and significant again as it was in Group 1. From these results it can be seen that domestic technology transfer impacts regions at both high and low innovation levels, but not at the medium level. It seems there is a U-shape relationship between domestic technology transfer and innovation level.

\subsection{The interactive effects}

$S \& T$ effort*FDI: In the overall regions the interactive effect was positive and significant on granted invention and utility model patents, while the impact among groups was quite different. Only the effect in Group 3 was similar to the overall regions. In Group 1 no interactive effect was found. In Group 2 the interactive effect was negative and significant on overall applications, but no significance was found on granted patents. In Group 3 the impact was only positively significant on granted invention patents. Simple slope analysis confirmed the significance of interactive effects found in Group 2 and Group 3 (Figure 1 and 2), such that both low and high S\&T effort exacerbated the negative effect of FDI on overall applications in Group 2 and on granted invention patents in Group 3. The impact was greater in Group 3 than in Group 2. The results suggest increasing investment in S\&T does assist in benefiting from FDI, and even has the opposite effect. 
S\&T effort*international trade: The effect of international trade coupled with S\&T effort was quite different among groups. In Group 1 the effect was positive on all DVs, but only significant on overall applications and overall granted patents at $\mathrm{p}<.05$. In Group 2 the effect was positive on all DVs as well, but it is only significant on granted invention patents at $\mathrm{p}<.01$. However, in Group 3 the coefficient was only found to be positively significant on granted utility model patents at $\mathrm{p}<.1$. For those significant interactive effects the simple slope analysis showed both low and high S\&T effort enhanced the positive effect of international trade on overall applications and granted patents in Group 1, on granted invention patents in Group 2, and on granted utility model patents in Group 3 (see Figure 36). From all these figures it can be seen the influence of increasing investment in S\&T was greater than decreasing the same amount of investment in S\&T. The influence was greater in high and medium innovation regions than in low innovation regions. It seems the more innovation the regions is, the more benefit it will get from international trade.

$S \& T$ effort*domestic technology transfer: The differences in the interactive effect between S\&T effort and domestic technology transfer among groups were greater than between S\&T effort and international interactions. In Group 1 no interactive effect was found. In Group 2 the interactive effect was positive and significant on overall applications and granted utility model patents. In Group 3 the coefficients were all negative and significant, but with different significant levels.

The simple slope analysis in Group 2 showed high funding for S\&T buffered the negative effect of domestic technology transfer, both on overall applications and granted utility model patents. Meanwhile low S\&T effort exacerbated the negative effect of domestic technology (see Figure 7 and 8). The results indicate S\&T effort moderates the relationship between domestic technology transfer and RIC positively in medium innovation regions. 
Analysis in Group 3, showed both high and low S\&T efforts enhanced the positive effect of domestic technology transfer on overall applications, overall granted patents, and granted invention patents. Figure 8-12 shows both high and low S\&T efforts buffered the negative effect of domestic technology transfer on granted utility model patents. The figures also indicate the effect of reducing S\&T effort is greater than increasing S\&T effort. Overall, S\&T effort plays a positive role in the relationship between domestic technology transfer and RIC in low innovation regions.

The reason for the differences among groups is probably the technology gap between buyerregion and seller-region, which can be inferred from Crespo and Fontoura (2007) and Sun and Du's (2010) argument on the impact of FDI. They argue the impact of FDI is contingent on the technology gap between the host and foreign countries. Since FDI is considered one means of technology transfer with international organizations, a similar argument can be made about domestic technology transfer among regions. High innovation regions in this study had the highest RIC on China, which means the gap between their technologies and technologies transferred from other regions was small. Hence there was not much they could get from transferred technologies to help them improve RIC. In medium innovation regions there was a gap between their own technologies and the advanced technologies transferred from other regions. By increasing their investment in S\&T activities and employing more advanced technologies with more S\&T funding, the regions could benefit a lot to develop RIC. However, there may be a big technology gap between what low innovation regions own and the technologies transferred from other regions. Consequently, the imported advanced technologies greatly improved the technology level of the region, but did not improve RIC (Figure 9 showed that the high versus low level of technology contract yielded the similar numbers of overall grant application). The reason may be the regions focused too much on importing from other regions, rather than innovation activities within the region. Whether the 
moderating role of S\&T effort between domestic interactions and RIC relates to the innovation level of a region needs further verification.

FDI*domestic technology transfer: The interactive effect between FDI and domestic technology transfer was quite different between groups. In Group 1 and Group 2 no interactive effect existed between the two interaction variables. In Group 3 it was positive and significant on overall granted patents but only at $\mathrm{p}<.1$. It was negative and significant on granted invention patents, but positive and significant on granted utility model patents. So it is difficult to tell how exactly the interactive effect will influence RIC in Group 3 according to regression results.

Taking FDI as a moderator, the simple slope analysis shows both low and high FDI enhanced the positive effect of domestic technology transfer on overall granted patents and granted invention patents. In Group 3 both an increase and decrease of FDI buffered the negative effect on domestic technology transfer on granted utility model patents (see Figure 13-15). When considering domestic technology transfer as a moderator (see Figure 16-18), both an increase and decrease of domestic technology transfer exacerbated the negative impact of FDI, which means domestic technology transfer does not help low innovation regions to benefit from FDI.

All in all, FDI and domestic technology transfer have no influence on each other's relationship with RIC in high and medium innovation regions. In low innovation regions FDI helps regions take advantage of domestic technology transfer. Domestic technology transfer does not influence the impact of FDI on RIC in the same way. 


\section{Conclusion}

Our study contributes into the innovation literatures in twofolds. First, the comparison among groups at different innovation levels enriches the literature of RIS and RIC, and reemphasises the importance of conducting IS research at the regional level, especially in countries that are unevenly developed on a national scale. Although studies at the national level enrich the bigger picture of the innovation phenomenon of the country, studies at the regional level uncover the story behind the big picture and provide a broader view. Second, the interactive effects between the drivers explored in China enrich the literature of NIS/RIS and NIC/RIC. Previous studies based on the NIS/RIS approach mainly focused on the impact of the factors alone, while this research finds RIC is also influenced by the interactive effects between factors.

Our study examined the innovation actors, inputs and interaction (domestic and international) as indicators of RIC in China. The direct effects can be summarized in the Table 6. This suggested that the common positive determinants across three groups are GDP (INPUT1), Import and export trade (DOMINTER 2), and Value of Domestic technology contract (DOMINTER3). Specifically, GDP positively impacted across four types of patents. The pivotal role of GDP suggests the phenomenon of "standing on the shoulders of others" exists in transitional countries. This means economic base and knowledge stock are critical in improving RIC. In the long term, the critical impacts of S\&T effort and skilled labour indicate innovation resources are important in developing countries to improve RIC.

In addition, the different impact among groups suggests the impact of innovation resources depends on the efficiency of utilization, not just the amount. The change in the impact of international interaction over the study period implies it takes time to take advantage of international interactions and particular conditions are needed to ensure positive spillovers from international interactions. The weak positive impact of domestic technology 
transfer suggests the technology market is important in RIC improvement, but it is not well developed in China. Moreover, the interactive effects between S\&T effort and interactions display that factors in RIS may affect RIC both directly and indirectly, and its impact may be influenced by other factors.

There are some limitations to our study that should be acknowledged. The first limitation relates to the data source. When using secondary data the quality of the data cannot be controlled, and measures of the variables have to be adjusted if the information available does not meet the requirements of the study. This being said, the fit of the data to the research question is a common concern. The second limitation concerns the variables included in the research framework. RIS is a complicated system that consists of many elements. However, it is impossible to include every factor and tell the whole story in one study. Hence, the omitted variables in the study may lead to some biases in the results. The third limitation refers to the measures of the variables. To measure RIC, patent counts are employed. However, not all innovations are patentable (Griliches, 1990) and patents are not the ultimate goal of enterprise and HEI (Bai \& Li, 2011). Besides, a large number of patents are applied for and granted to individuals in China, which measures the RIC of individual residents within a region, but the financial and human resource inputs to those activities are unknown. This study did not consider the ownership of patents, which may lead to some biases in the results. The final limitation is the time lag between IVs and DVs. In this study it is assumed the time lags are the same between IVs and granted invention patents, and between IVs and granted utility model patents. But according to China's Patent Law the granting process is simpler for utility model patents than for invention patents and it takes less time as well. Therefore, employing the same time lag for different categories of patents may lead to biases in the impacts of drivers on these two categories. 
With regard to international interactions, the impact of imports and exports can be investigated separately to see which strategy works better. For FDI, alternative indicators, such as the assets of foreign invested enterprises (Xian \& Yan, 2005), rather than the annual inflow of FDI, could be considered. Besides, how the FDI is used could provide more insights into how FDI influences RIC (Fu, 2008) and how different types of FDI generate different spillovers (Driffield \& Love, 2007). It could also provide a better understanding of the ways FDI is spent and the types of FDI that should be the focus of future research based in the context of China.

The role of S\&T investment between domestic and international interactions and RIC, S\&T effort does not fully represent absorptive capacity, though it is commonly used. As the quality of labour force will influence the capability to absorb advanced technologies (Anwar \& Nguyen, 2010; Chi, Yu, \& Li, 2008), skilled labour should be considered when measuring absorptive capacity in the future. Moreover, the unexpected negative effect of S\&T effort on the impact of domestic technology transfer and FDI in different phases and in different groups calls for further verification.

Despite the limitations, our findings provide policy implications for both national and regional governments and policy makers. First, the existence of interactive effects between drivers suggests both national and regional governments need to pay attention to the effect of a single factor, as well as its interactive effect with other factors, when developing strategies or policies to improve RIC in China.

Second, the changing impact of drivers over time implies both national and regional governments need to know the recent affect of a factor on RIC and how the strategies related to that factor worked in the past prior to developing new strategies or adjusting policies to improve RIC. The changing impact also indicates governments should modulate innovation strategies and policies in terms of the change of the impact. Specifically, the impact of 
innovation actors in the two phases suggests it is good for governments to continue encouraging HEI to take advantage of the research resources they have and exert spin-offs to serve the development of industries. Developing further incentives for enterprises to put more effort into innovation activities will help achieve the objective of developing an enterpriseoriented NIS/RIS.

Third, the findings from the comparison of groups show successful strategies and policies may not be adaptable to regions at different innovation levels, and regional governments should not blindly follow the successful experiences of other regions. The national government should give more autonomy to the regional governments, so they can create more effective strategies and policies suitable to their own situations.

In regards to innovation actors, governments in low innovation regions need to accelerate the reform of enterprise systems and HEI and provide more incentives for them to initiate innovation activities. In terms of input factors, all regions need to enhance the efficiency of resources utilizations and low innovation regions need to make policies designed to attract more skilled talent. For FDI and international trade, high innovation regions need to place more focus on how to gain positive spillovers, as they already have a large inflow of FDI and international trade. Meanwhile low innovation regions need to develop conditions for positive spillovers and attracting more FDI inflow.

Overall, our study makes both theoretical and practical contributions to NIS/RIS and NIC/RIC through three key findings: interactive effects, impact changes over time, and differences in impact of drivers on RIC among different innovation regions in China. 
Table 6: A summary of common direct effects between RIC determinants and outcomes.

\begin{tabular}{|c|c|c|c|c|}
\hline Innovation activity & RIC determinants ${ }^{14}$ & G1 & G2 & G3 \\
\hline \multirow[t]{9}{*}{ Overall patent applications } & ACTOR1 & & + & + \\
\hline & ACTOR 2 & & & \\
\hline & INPUT1 & + & + & + \\
\hline & INPUT 2 & + & + & \\
\hline & INPUT 3 & - & & + \\
\hline & INPUT 4 & & + & + \\
\hline & DOMINTER1 & - & - & - \\
\hline & DOMINTER 2 & + & + & + \\
\hline & DOMINTER 3 & + & + & + \\
\hline \multirow[t]{9}{*}{ Overall granted patents } & ACTOR1 & & & \\
\hline & ACTOR 2 & & & \\
\hline & INPUT1 & + & + & + \\
\hline & INPUT 2 & & & \\
\hline & INPUT 3 & & & + \\
\hline & INPUT 4 & & & + \\
\hline & DOMINTER1 & & & - \\
\hline & DOMINTER 2 & & & + \\
\hline & DOMINTER 3 & & & \\
\hline \multirow[t]{9}{*}{ Granted invention patents } & ACTOR1 & & & - \\
\hline & ACTOR 2 & & - & - \\
\hline & INPUT1 & + & + & + \\
\hline & INPUT 2 & + & & + \\
\hline & INPUT 3 & - & + & + \\
\hline & INPUT 4 & - & - & + \\
\hline & DOMINTER1 & - & - & - \\
\hline & DOMINTER 2 & + & + & - \\
\hline & DOMINTER 3 & + & & + \\
\hline \multirow[t]{9}{*}{ Granted utility model patents } & ACTOR1 & - & & + \\
\hline & ACTOR 2 & & & \\
\hline & INPUT1 & + & + & + \\
\hline & INPUT 2 & & & \\
\hline & INPUT 3 & - & & \\
\hline & INPUT 4 & & & \\
\hline & DOMINTER1 & - & - & - \\
\hline & DOMINTER 2 & + & + & + \\
\hline & DOMINTER 3 & + & & \\
\hline
\end{tabular}

14 (ACTOR1) No. of HEIs; (ACTOR2) No. of large and medium-sized industrial enterprises; (INPUT1) GDP; (INPUT 2) Funding for S\&T, (INPUT 3); fulltime employed scientists and engineers; (INPUT 4) Employment rate; (DOMINTER 1) Inward FDI; (DOMINTER 2) Import and export trade; (DOMINTER 3) Value of Domestic technology contract 


\section{Reference}

Acs, Z. J., Anselin, L., \& Varga, A. (2002). Patents and innovation counts as measures of regional production of new knowledge. Research policy, 31(7), 1069-1085.

Acs, Z. J., \& Audretsch, D. B. (1989). Patents as a Measure of Innovative Activity. Kyklos, 42(2), 171-180. doi: 10.1111/j.1467-6435.1989.tb00186.x

Anwar, S., \& Nguyen, L. P. (2010). Absorptive capacity, foreign direct investment-linked spillovers and economic growth in Vietnam. Asian Business \& Management, 9(4), 533-570.

Archambault, É. (2002). Methods for using patents in cross-country comparisons. Scientometrics, 54(1), 15-30. doi: 10.1023/a:1015654903218

Asheim, B. T., Coenen, L., \& Svensson-Henning, M. (2003). Nordic SMEs and Regional Innovation Systems Sweden: Nordic Industrial Fund Center for Innovation and Commercial Development.

Asheim, B. T., \& Isaksen, A. (1997). Location, agglomeration and innovation: Towards regional innovation systems in Norway? European Planning Studies, 5(3), 299-330.

Asheim, B. T., \& Vang, J. (2006). Regional innovation systems in Asian countries: A new way of exploiting the benefits of transnational corporations. Innovation: Management, Policy \& Practice, 8(1-2), 27-44.

Baark, E. (2007). Knowledge and innovation in china: Historical legacies and emerging institutions. Asia Pacific Business Review, 13(3), 337-356.

Bai, J., \& Li, J. (2011). Regional innovation efficiency in China: The role of local government. Innovation : Management, Policy \& Practice, 13(2), 142-153.

Baltagi, B. H. (2008). Econometric Analysis of Panle Data (4th ed.). West Sussex, UK: John Wiley \& Sons, Ltd.

Barbieri, E., Di Tommaso, M. R., \& Huang, M. (2010). Industrial development policy and innovation in Southern China: Government targets and firms' behaviour. European Planning Studies, 18(1), 83-105.

Buckley, P. J., Clegg, J., \& Wang, C. (2002). The Impact of Inward FDI on the Performance of Chinese Manufacturing Firms. Journal of International Business Studies, 33(4), 637-655.

Carlsson, B., Jacobsson, S., Holmen, M., \& Rickne, A. (2002). Innovation systems: Analytical and methodological issues. Research policy, 31(2), 233-245.

Chen, J., Chen, Y., \& Yu, F. (2007). The impact of FDI on China's regional innovation capacity. Science Research Management, 28(1), 7-13 (in Chinese).

Chen, K., \& Kenney, M. (2007). Universities/Research Institutes and Regional Innovation Systems: The Cases of Beijing and Shenzhen*. World Development, 35(6), 1056.

Chi, R., Yu, X., \& Li, Z. (2008). The differences in the efficiency of S\&T innovation between East and West China and the reasons for the differences. China Soft Science Magazine, 8, 128-132 (in Chinese).

Chuang, Y.-C., \& Hsu, P.-F. (2004). FDI, trade, and spillover efficiency: evidence from China's manufacturing sector. Applied Economics, 36(10), 1103-1115. doi: $10.1080 / 0003684042000246812$

Chung, S. (2002). Building a national innovation system through regional innovation systems. Technovation, 22(8), 485-491.

Cohen, W. M., \& Levinthal, D. A. (1989). Innovation and Learning: The Two Faces of R \& D. The Economic Journal, 99(397), 569-596.

Cohen, W. M., \& Levinthal, D. A. (1990). Absorptive capacity: A new perspective on learning and innovation. Administrative Science Quarterly, 35(1), 128. 
Cooke, P., Uranga, M. G., \& Etxebarria, G. (1997). Regional innovative systems: Institutional and organisational dimensions. Research policy, 26(4,5), 475-491.

Cooke, P., Uranga, M. G., \& Etxebarria, G. (1998). Regional systems of innovation: An evolutionary perspective. Environment and Planning A, 30, 1563-1584.

Crespo, N., \& Fontoura, M. P. (2007). Determinant Factors of FDI Spillovers - What Do We Really Know? World Development, 35(3), 410-425. doi: 10.1016/j.worlddev.2006.04.001

D’Allura, G., Galvagno, M., \& Mocciaro Li Destri, A. (2012). Regional Innovation Systems: A Literature Review. Business Systems Review, 1(1), 139-156.

Doloreux, D. (2002). What should we know about regional systems of innovation. Technology in society, 24, 243-263.

Doloreux, D. (2003). Regional innovation systems in the periphery: The case of the beauce in quebec. International Journal of Innovation Management, 7(1), 67-94.

Doloreux, D., \& Parto, S. (2009). Regional Innovation Systems A Critical Review. Regional Innovation Systems: A Critical Review

Driffield, N., \& Love, J. H. (2007). Linking FDI motivation and host economy productivity effects: conceptual and empirical analysis. Journal of International Business Studies, 38(3), 460-473. doi: 10.1057/palgrave.jibs.8400268

Etzkowitz, H. (2008). The Triple Helix: University-Industry-Government Innovation in Action. New York: Routledge.

Evangelista, R., Iammarino, S., Mastrostefano, V., \& Silvani, A. (2001). Measuring the regional dimension of innovation. Lessons from the Italian Innovation Survey. Technovation, 21(11), 733-745.

Fan, P. (2011). Innovation capacity and economic development: China and India. Economic change and restructuring, 44(1), 49-49-73. doi: 10.1007/s10644-010-9088-2

Fleck, J. (1993). Configurations: Crystallizing contingency. International Journal of Human Factors in Manufacturing, 3(1), 15-36.

Freeman, C. (2004). Technological infrastructure and international competitiveness. Industrial and Corporate Change, 13(3), 541-569. doi: 10.1093/icc/dth022

Fritsch, M. (2002). Measuring the quality of regional innovation systems: A knowledge production function approach. International Regional Science Review, 25(1), 86-101.

Fritsch, M., \& Schwirten, C. (1999). Enterprise-University co-operation and the role of public research institutions in regional innovation systems. industry and Innovation, 6(1), 69-83.

$\mathrm{Fu}, \mathrm{X}$. (2008). Foreign direct investment, absorptive capacity and regional innovation capabilities: Evidence from China. Oxford Development Studies, 36(1), 89-110.

Fu, X., \& Gong, Y. (2011). Indigenous and Foreign Innovation Efforts and Drivers of Technological Upgrading: Evidence from China. World Development, 39(7), 12131225. doi: 10.1016/j.worlddev.2010.05.010

Furman, J. L., Porter, M. E., \& Scott, S. (2002). The determinants of national innovative capacity. Research policy, 31(6), 899-933.

Giuliani, E., Rabellotti, R., \& Dijk, M. P. v. (Eds.). (2005). Clusters Facing Competition: The Importance of External Linkages. Aldershot: Ashgate.

Griliches, Z. (1990). Patent Statistics as Economic Indicators: A Survey. Journal of Economic Literature, 28(4), 1661-1707.

Guan, J. C., Yam, R. C. M., \& Mok, C. K. (2005). Collaboration between industry and research institutes/universities on industrial innovation in Beijing, China. Technology Analysis \& Strategic Management, 17(3), 339.

Hagedoorn, J., \& Cloodt, M. (2003). Measuring innovative performance: Is there an advantage in using multiple indicators? Research policy, 32(8), 1365. 
Hanousek, J., Kocenda, E., \& Maurel, M. (2011). Direct and indirect effects of FDI in emerging European markets: A survey and meta-analysis. Economic Systems, 35, 301-322.

Howells, J. (1999). Regional systems of innovation. In D. Archibugi, J. Howells \& J. Michie (Eds.), Innovation Policy in a Global Economy. Cambridge: Cambridge University Press.

Hu, A. G., \& Jefferson, G. H. (2002). FDI Impact and Spillover: Evidence from China's Electronic and Textile Industries. World Economy, 25(8), 1063-1076.

Hu, A. G., Jefferson, G. H., \& Qian, J. (2005). R\&D and Technology Transfer: Firm-Level Evidence from Chinese Industry. The Review of Economics and Statistics, 87(4), 780786.

Hu, M.-C., \& Mathews, J. A. (2005). National innovative capacity in East Asia. Research policy, 34(9), 1322-1349.

Hu, M.-C., \& Mathews, J. A. (2008). China's national innovative capacity. Research policy, 37(9), 1465-1479.

Huang, J.-T. (2004). Spillovers from Taiwan, Hong Kong, and Macau investment and from other foreign investment in Chinese industries. Contemporary Economic Policy, 22(1), 13-25. doi: 10.1093/cep/byh002

Huang, J. (2007). Reform of management mechanism on public research institutes and the international comparison. Science of Science and management of $S \& T, 12,53-55$ (in Chinese).

Iammarino, S. (2005). An evolutionary integrated view of regional systems of innovation: Concepts, measures and historical perspectives. European Planning Studies, 13(4), 497-519.

Ji, B., \& Zhao, Y. (Eds.). (2008). China Towards an Innovation Country: China's Innovation Index. Beijing: Renmin University Press (in Chinese).

Jiang, D., \& Xia, L. (2005). The empir ical study of the function of FDI on innova tion in China's high-tech industries. World Economy, 8, 3-10 (in Chinese).

Johnson, W. H. A., \& Liu, Q. (2011). Patenting and the role of technology markets in regional innovation in China: An empirical analysis. Journal of High Technology Management Research, 22(1), 14.

Kostopoulos, K., Papalexandris, A., Papachroni, M., \& Ioannou, G. (2010). Absorptive capacity, innovation, and financial performance. Journal of Business Research, In Press, Corrected Proof. doi: 10.1016/j.jbusres.2010.12.005

Krammer, S. (2009). Drivers of national innovation in transition: Evidence from a panel of Eastern European countries. Research policy, 38(5), 845.

Lai, M., Peng, S., \& Bao, Q. (2006). Technology spillovers, absorptive capacity and economic growth. China Economic Review, 17(3), 300-320.

Li, J., \& Li, Z. (2008). The course and achievements of establishing science and technology innovation system in China. Jilin University Journal Social Sciences Edition, 48(6), 124-132 (in Chinese).

Li, X. (2009). China's regional innovation capacity in transition: An empirical approach. Research policy, 38(2), 338.

Li, X., Liu, X., \& Parker, D. (2001). Foreign direct investment and productivity spillovers in the Chinese manufacturing sector. Economic Systems, 25(4), 305-321. doi: 10.1016/s0939-3625(01)00029-2

Liang, Y. (2008). Why Are China's Exports Special? The Role of FDI, Regional Trade and Government Policies. Chinese Economy, 41(6), 99-118.

Liao, S.-h., Wu, C.-c., Hu, D.-c., \& Tsui, K.-a. (2010). Relationships between knowledge acquisition, absorptive capacity and innovation capability: an empirical study on 
Taiwan's financial and manufacturing industries. Journal of Information Science, 36(1), 19-35.

Lin, H.-1., \& Lin, E. S. (2010). FDI, Trade, and Product Innovation: Theory and Evidence. Southern Economic Journal, 77(2), 434-464.

Liu, X., \& Wang, C. (2003). Does foreign direct investment facilitate technological progress?: Evidence from Chinese industries. Research policy, 32(6), 945-953. doi: 10.1016/s0048-7333(02)00094-x

Liu, X., \& White, S. (1997). The relative contributions of foreign technology and domestic inputs to innovation in Chinese manufacturing industries. Technovation, 17(3), 119125.

Liu, X., \& Zou, H. (2008). The impact of greenfield FDI and mergers and acquisitions on innovation in Chinese high-tech industries. Journal of World Business, 43(3), 352364. doi: 10.1016/j.jwb.2007.11.004

Liu, Z. (2002). Foreign Direct Investment and Technology Spillover: Evidence from China. Journal of Comparative Economics, 30(3), 579-602. doi: 10.1006/jcec.2002.1789

Liu, Z. (2008). Foreign direct investment and technology spillovers: Theory and evidence. Journal of Development Economics, 85(1-2), 176-193. doi: 10.1016/j.jdeveco.2006.07.001

Lundvall, B.- $\AA$. (2007). National Innovation Systems-Analytical Concept and Development Tool. Industry and Innovation, 14(1), 95.

Mathews, J. A., \& Hu, M.-C. (2007). Enhancing the Role of Universities in Building National Innovative Capacity in Asia: The Case of Taiwan. World Development, 35(6), 1005.

NDRC. National Development and Reform Commission. Retrieved 10.25, 2011, from http://www.ndrc.gov.cn/zxqy/zcfg/t20050715_36687.htm

Nelson, R. R. (Ed.). (1993). National innovation systems: A comparative analysis. New York: Oxford University Press.

Oliver, C. (1997). The influence of institutional and task environment relationships on organizaitonal performance: The Canadian contstruction industry. The Journal of Management Studies, 34(1), 99-124.

Pan, T.-W. (2007). Measuring the Efficiency of National Innovation System. Journal of American Academy of Business, Cambridge, 11(2), 176.

Park, Y., \& Park, G. (2003). When does a national innovation system start to exhibit systemic behavior? Industry and Innovation, 10(4), 403.

Peng, M. W., \& Wang, D. Y. (2000). Innovation Capability and Foreign Direct Investment: Toward a Learning Option Perspective1. Management International Review, 40, 7993.

Porter, M. E. (1990). The competitive advantage of nations. New York: Free Press.

Rothwell, R. (1992). Industrial innovation and government environmental regulation: Some lessons from the past. Technovation, 12(7), 447-458.

Spulber, D. F. (2008). Innovation and international trade in technology. Journal of Economic Theory, 138(1), 1-20. doi: 10.1016/j.jet.2007.06.002

Sun, Y., \& Du, D. (2010). Determinants of industrial innovation in China: Evidence from its recent economic census. Technovation, 30(9-10), 540-550. doi: 10.1016/j.technovation.2010.05.003

Tian, X. (2007). Accounting for Sources of FDI Technology Spillovers: Evidence from China. Journal of International Business Studies, 38(1), 147-159.

Trajtenbery, M. (1990). Patents as indicators of innovation, Economic Analysis of Product Innovation. Cambridge, MA: Harvard University Press.

Wagner, S., \& Liegsalz, J. (2011). Patent examination at the State Intellectual Property office in China. Paper presented at the Academy of Managment Annual Meeting, San Antonio, Texas, USA. 
William, J. A., \& Balaji, S. C. (1979). Government Intervention and Innovation in Industry: A Policy Framework. Sloan Management Review (pre-1986), 20(3), 3.

Wu, J., Zhou, Z., \& Liang, L. (2010). Measuring the performance of Chinese regional innovation systems with two-stage DEA-based model. International Journal of Sustainable Society, 2(1), 85-99.

Xian, G., \& Yan, B. (2005). The spillover effects of FDI on China's innovation capability. World Economy, 10, 18-26 (in Chinese).

Zabala-Iturriagagoitia, J. M., Voigt, P., Gutiérrez-Gracia, A., \& Jiménez-Sáez, F. (2007). Regional innovation systems: How to assess performance. Regional Studies, 41(5), 661-672.

Zhang, J., \& Rogers, J. D. (2009). The technological innovation performance of Chinese firms: the role of industrial and academic R\&D, FDI and the markets in firm patenting. International Journal of Technology Management, 48(4), 518-543.

Zhao, D., Gao, W., \& Li, Y. (2011). Study on the influence on regional innovative capability by the means of konwledge transfer -- Based on the analysis of the data during 20012008 in China. Science \& Technology Progress and Policy, 28(16), 32-36 (in Chinese).

Zhong, X., \& Yang, X. (2007). Science and technology policy reform and its impact on China's national innovation system. Technology in Society, 29(3), 317-325.

Zhu, D., \& Tann, J. (2005). A regional innovation system in a small-sized region: A clustering model in Zhongguancun Science Park. Technology Analysis \& Strategic Management, 17(3), 375. 